\title{
Treatment with dopamine $\beta$-hydroxylase (DBH) inhibitors prevents morphine use and relapse-like behavior in rats
}

\author{
Małgorzata Frankowska ${ }^{1}$ (D ) Paulina Surówka ${ }^{1}$ Agata Suder ${ }^{1} \cdot$ Renata Pieniążek $^{1} \cdot$ Renata Pukło $^{2}$. \\ Joanna Jastrzębska ${ }^{2} \cdot$ Władysława A. Daniel $^{2} \cdot$ Małgorzata Filipp $^{1} \cdot$ Magdalena Zadrożny-Bujalska $^{3}$. \\ Patrycja Kleczkowska ${ }^{3,4}$
}

Received: 10 February 2021 / Revised: 21 June 2021 / Accepted: 29 June 2021 / Published online: 8 July 2021

(c) The Author(s) 2021

\begin{abstract}
Background Opioid use disorders are serious contributors to the harms associated with the drug use. Unfortunately, therapeutic interventions for opioid addicts after detoxification have been limited and not sufficiently effective. Recently, several studies have led to promising results with disulfiram (DSF), a dopamine $\beta$-hydroxylase (DBH) inhibitor, showing that it is a potent agent against not only alcohol but also addiction to various drugs.

Materials and methods This study was designed to examine whether DSF and nepicastat (NEP; another DBH inhibitor) modify morphine intake and reinstatement of seeking-behavior using the rat model of intravenous morphine self-administration. Additionally, we intended to estimate the effects of both inhibitors on the locomotor activity as well as on extracellular dopamine and its metabolite levels in the nucleus accumbens using microdialysis in naive rats.

Results We demonstrated that both DBH inhibitors reduced responding to morphine self-administration. Moreover, DSF and NEP administered acutely before reinstatement test sessions consistently attenuated the reinforcing effects of morphine and a morphine-associated conditioned cue. The observed effects for lower doses $(6.25-25 \mathrm{mg} / \mathrm{kg}$; ip) of both DBH inhibitors seem to be independent of locomotor activity reduction and dopamine level in the nucleus accumbens. Neither DSF nor NEP administered daily during morphine abstinence with extinction training sessions had any effect on active lever-responding and changed the reinstatement induced by morphine priming doses. Reinstatement of drug-seeking behavior induced by a conditioned cue previously associated with morphine delivery was attenuated following repeated administration of DSF or NEP during the abstinence period.

Conclusion These results seem to point to the significance of DBH inhibition as a potential pharmacotherapy against morphine use disorders.
\end{abstract}

Małgorzata Frankowska

frankow@if-pan.krakow.pl

1 Department of Drug Addiction Pharmacology, Maj Institute of Pharmacology, Polish Academy of Sciences, ul. Smętna 12, 31-343 Kraków, Poland

2 Department of Pharmacokinetics and Drug Metabolism, Maj Institute of Pharmacology, Polish Academy of Sciences, ul. Smętna 12, 31-343 Kraków, Poland

3 Department of Department of Pharmacodynamics, Centre for Preclinical Research and Technology, Medical University of Warsaw, ul. Banacha 1B, 02-097 Warsaw, Poland

4 Military Institute of Hygiene and Epidemiology, ul. Kozielska 4, 01-163 Warsaw, Poland 


\section{Graphic abstract}

MODEL

SELF-ADMINISTRATION EXTINCTION TRAINING

MORPHINE

$0.56 \mathrm{mg} / \mathrm{kg} /$ infusion

+ conditioned cue
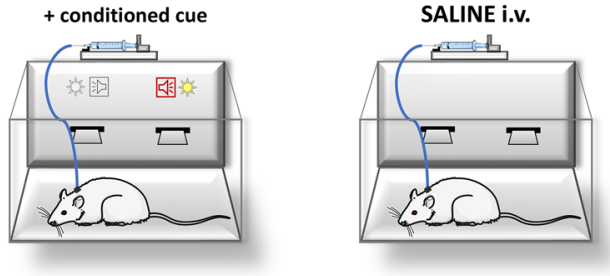

EFFECT OF DOPAMINE B-HYDROXYLASE INHIBITORS

TREATMENT

ACUTE

DISULFIRAM

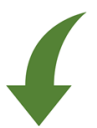

NEPICASTAT

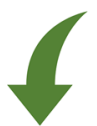

REINSTATEMENT OF SEEKING-BEHAVIOUR

Conditioned cue

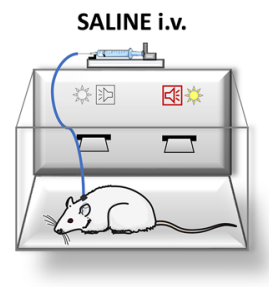

REPEATED

ACUTE

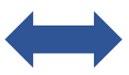

REPEATED
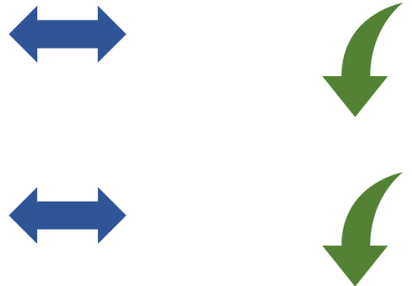

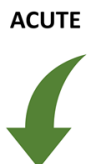

REPEATED

Morphine (i.p.) priming

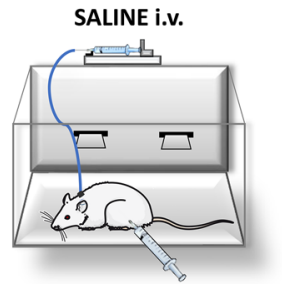

ACUTE

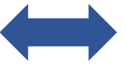

1

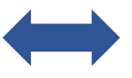

Keywords Disulfiram $\cdot$ Locomotor activity $\cdot$ Microdialysis $\cdot$ Morphine self-administration $\cdot$ Nepicastat $\cdot$ Rats $\cdot$ Seekingbehavior

\section{Introduction}

According to the Department of Mental Health and Substance Abuse (World Health Organization) as well as the European Monitoring Center for Drugs and Drug Addiction, the opioid use disorders (OUD), including compulsive using of pain relievers (e.g. morphine, tramadol), heroin, and synthetic opioids, are serious contributors to the harms associated with the drug use in the world [1]. The beginnings of the opioid overuse epidemic date back to the mid-1980s, when shifts in clinical practice planted the seed for the sharp uptick in prescribing opioids. During the last 10 years, an increasing trend in drug-related acute emergency cases was observed (c.a. 60\%), particularly those caused by opioids and opiates. Moreover, OUD represents the most common form of addiction among entrants to specialized treatment $[1,2]$. At present, unfortunately, the effectiveness of therapeutic interventions for opioid addicts after detoxification has been limited only to a substitution therapy [3].

On the whole, the knowledge about the role of dopamine in addiction, as the primary mediator of drug reward properties, has been solidified [4]. Thus, the drugs of abuse induced a large release of dopamine in limbic areas, specifically nucleus accumbens $[4,5]$. The experimental results from the research into the role of dopamine as a primary neurotransmitter in OUD have been fraught with disagreement $[6,7]$. The first evidence of the importance of another catecholamine, noradrenaline, in the mediation of OUD was emphasized at the beginning of the ' $70 \mathrm{~s}$ of the last century. For example, a series of experiments showed that AMPT, a tyrosine hydroxylase inhibitor, attenuated self-administration of morphine in rodents [8] and nonhuman primates [9] and that the mechanism was linked to the reduction of noradrenaline and dopamine synthesis. Moreover, U-14,624 or FLA-57, dopamine $\beta$-hydroxylase (DBH) inhibitors that convert dopamine into noradrenaline in noradrenergic neurons, attenuated the oral intake of morphine in rats $[10,11]$. Recent studies demonstrated that other DBH inhibitors, like disulfiram (DSF) or nepicastat (NEP), effectively attenuated reinstatement of cocaine-seeking behavior in rats [12-15]. DSF, apart from inhibition of aldehyde dehydrogenase that results in acetaldehyde accumulation upon alcohol ingestion, also inhibits the DBH enzyme [16, 17]. Compared to DSF, NEP demonstrates significantly higher potency to inhibit DBH, without exerting the effect on other enzymes [18]. Several of studies revealed that both DBH inhibitors administered acutely reduced noradrenaline levels in the prefrontal cortex and nucleus accumbens, and effectively 
increased dopamine release only in the prefrontal cortex, without the influence on the nucleus accumbens $[15,19,20]$.

Alcohol and opioids are commonly used together, while alcohol contributes to many opioid overdose deaths. The last recommendations for alcohol use disorder treatment present the use of naltrexone, acamprosate, and DSF as the first-line treatments for patients with alcohol use disorder, while the standard treatment for OUD proposes methadone, buprenorphine, and naltrexone [21-23]. Nevertheless, current clinical trials do not advise using inhibitors of DBH in the comorbidity of alcohol and OUD.

This study was designed to examine whether DSF and NEP modify behavioral responses to morphine and reinstatement of the drug-seeking-behavior using an animal model of intravenous self-administration. Importantly, to broaden our understanding of the mechanism of action of both above DBH inhibitors, we assessed the effects of acute and repeated treatment with DSF and NEP on locomotor activity and on extracellular dopamine release and its metabolite levels in the nucleus accumbens using microdialysis in freely moving naive rats.

\section{Materials and methods}

\section{Animals}

Experimentally naive male Wistar rats (225-250 g) delivered by a licensed breeder (Charles River, Munich, Germany) were housed in standard laboratory conditions $\left(22 \pm 2{ }^{\circ} \mathrm{C}\right.$ temperature; $45-65 \%$ humidity; a 12 -h light-dark cycle with lights on at 6.00 a.m.). Animals had free access to food and water during the 7-day habituation period (unless initial training sessions, see below). All experiments were conducted during the light phase of the light-dark cycle (between 7.00 a.m. and 4.00 p.m.). The experiments were carried out in accordance with the European Directive 2010/63/EU and were approved by the Ethical Committee at Maj Institute of Pharmacology, Polish Academy of Sciences, Kraków (permits no.: 1190/2015 and 336/2017).

\section{Drugs}

Morphine (Polfa Warszawa, Poland) was dissolved in sterile $0.9 \% \mathrm{NaCl}$ and given intravenously $(0.1 \mathrm{ml} /$ infusion $)$ or intraperitoneally (ip; $1 \mathrm{ml} / \mathrm{kg}$ ). Disulfiram (DSF; $N, N, N$, $N$ tetraethylthiuram disulfide, Polfa Warszawa, Warszawa, Poland) suspended in $0.1 \%$ methylcellulose (Sigma Aldrich, St. Louis, MO, USA) and nepicastat (NEP, BOC Sciences New Yorke, NY, USA) suspended in saline with $1.5 \%(\mathrm{v} / \mathrm{v})$ DMSO (Sigma Aldrich, St. Louis, MO, USA) and 1.5\% ethanol (POCH, Gliwice, Poland) were pre-administered $120 \mathrm{~min}$, ip $(1 \mathrm{ml} / \mathrm{kg})$. Doses and pre-administration time of both DBH inhibitors were chosen based on previous research $[13,14,24]$.

\section{Behavioral experiments}

\section{Morphine self-administration and extinction training}

After a week of habituation to the animal facility, all animals were trained to press the lever for water reinforcement on a fixed ratio (FR) 1 schedule of reinforcement in standard operant chambers (Med-Associates, St. Albans, VT, USA). After the lever-press training and after giving the animals free access to water, rats were chronically implanted with a silastic catheter in the external jugular vein. Deep anesthesia was produced by a combination of ketamine hydrochloride (75 mg/kg ip; Bioketan; Biowet, Pulawy, Poland) and xylazine (5 mg/kg ip; Sedazin; Biowet, Pulawy, Poland). Following surgery, rats were kept individually in standard rat home cages with free access to water and food and catheters were flushed every day $(0.1 \mathrm{ml}$ heparin $(70 \mathrm{U} / \mathrm{ml})$ with saline solution or cephazolin solution $(10 \mathrm{mg} / \mathrm{ml}$; Biochemie $\mathrm{GmbH}$, Kundl, Austria). Morphine self-administration testing began at least 7 days following surgery and was conducted in experimental chambers (Med-Associates, St. Albans, VT, USA) during 2-h daily sessions performed 6 days/week (maintenance). The infusion of morphine was associated with a conditioned stimulus (5 s), a tone $(2000 \mathrm{~Hz} ; 15 \mathrm{~dB})$ and the illumination of the stimulus light directly above the active lever. Following each drug injection, there was a $20 \mathrm{~s}$ time-out period during which the response was recorded but had no programmed consequences. Response on the inactive lever never resulted in morphine delivery.

Initial training for morphine self-administration consisted of daily sessions during which each active lever press was reinforced with a morphine infusion at a dose of $0.56 \mathrm{mg} / \mathrm{kg}$ according to the FR1 schedule of reinforcement and the following acquisition. After 3 sessions of morphine self-administration, the response requirements were increased to FR3, then to FR5 for another 3 sessions, and were maintained till the end of the experiment. Animals encountering problems with the catheters during the self-administration period or rats that did not fulfill the self-administration acquisition/ maintenance criterion (see below) were excluded from further experiments.

After morphine self-administration (at least 20 days), once the rats met the acquisition/maintenance criterionthat is (i) pressing the active lever for 3 successive days with $15 \%$ or less variation, on average and (ii) total intake of $90 \mathrm{mg}$ morphine during the entire experiment-separate groups of rats underwent extinction training and reinstatement tests. The extinction sessions took place in experimental cages and covered 2-h daily training sessions neither with morphine provision nor exposure to a conditioned stimulus. 
After extinction training, covering not less than 14-daily sessions, the number of responses on the active lever fell below $15 \%$, in comparison to the number of activations of that lever scored at the maintenance phase of morphine selfadministration. Animals that failed to achieve an extinction training criterion were removed from experiments in reinstatement seeking-behavior. The animals underwent trial for the response reinstatement triggered by a non-contingent morphine injection or a conditioned cue (light + tone). The latter one was earlier associated with morphine selfadministration. During 2-h reinstatement sessions active lever responding was rewarded with an intravenous saline injection.

Pharmacological tests Experiment 1: Morphine selfadministration, extinction training, and reinstatement of drug-seeking behavior

The group of rats ( $n=10$ rats/group) that underwent a protocol of morphine self-administration and extinction training was used in reinstatement tests. Each rat underwent the reinstatement procedure in which either a morphineassociated cue or morphine solely $(2.5-10 \mathrm{mg} / \mathrm{kg}$, ip $)$ was presented. The order of morphine injections was balanced according to a Latin square design, and the test sessions were separated by at least two to three baseline days of morphine self-administration (Fig. 1).

Experiment 2: The effect of acute administration of DSF or NEP on morphine self-administration

In pharmacological studies, the new cohort of rats divided into two separate groups and trained to self-administer morphine were acutely pretreated with either DSF $(12.5-50 \mathrm{mg} /$ $\mathrm{kg} ; \mathrm{n}=9)$, or NEP $(12.5-50 \mathrm{mg} / \mathrm{kg} ; \mathrm{n}=9)$, or the corresponding vehicles $120 \mathrm{~min}$ before the self-administration sessions. The order of injections was balanced according to a Latin square design, and the test sessions were separated by at least two to three baseline days of morphine selfadministration (Fig. 1).

Experiment 3: The effect of repeated administration of DSF or NEP on extinction training and reinstatement of drugseeking behavior

A separate cohort of rats trained to self-administered morphine was divided into separate groups and pretreated with DSF $(50 \mathrm{mg} / \mathrm{kg} ; n=11)$, NEP $(25 \mathrm{mg} / \mathrm{kg} ; n=8)$ or the corresponding vehicles (control groups; $n=7$ and 8 ) $120 \mathrm{~min}$ before the extinction session for 14 sequential

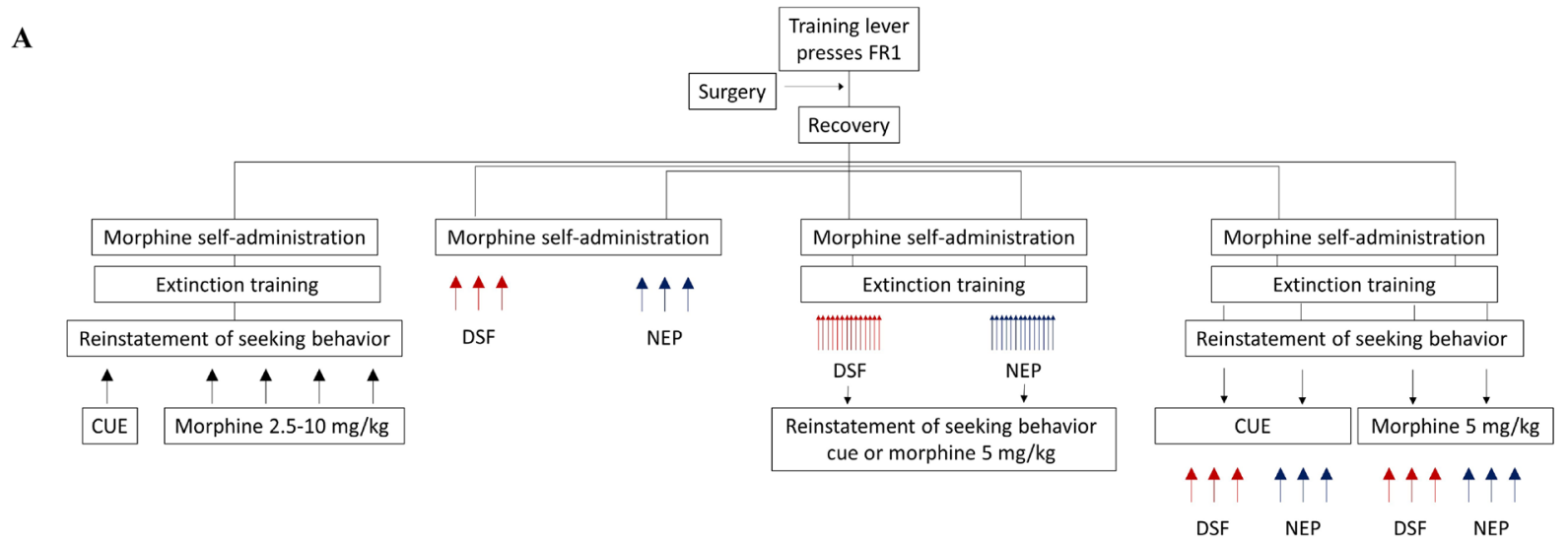

B

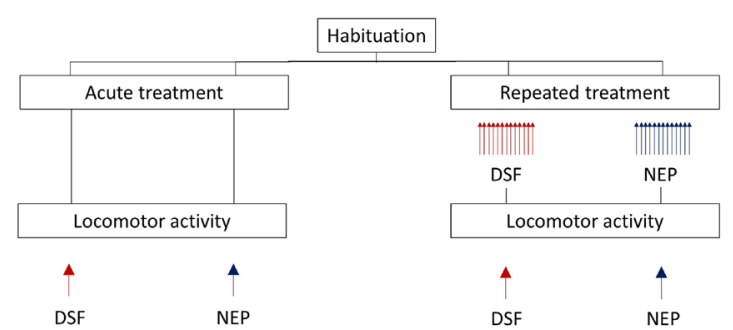

Fig. 1 Experimental design of behavioral experiments including morphine self-administration, extinction training and cue- or morphineinduced reinstatement of seeking behavior (A), locomotor activity (B) or microdialysis procedures (C) and effects of disulfiram (DSF)

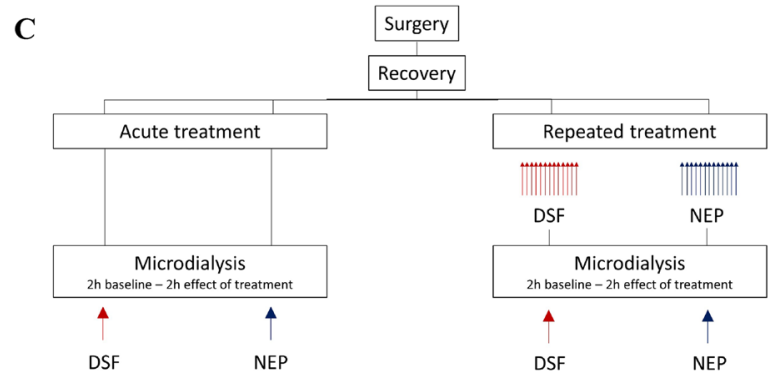

or nepicastat (NEP). Each line represents a separate group of rats. Arrows represent exposure to a reinstatement stimulus or administration of drugs 
days. The responses on active and inactive lever presses were compared to the control group. Following extinction training, morphine $(5 \mathrm{mg} / \mathrm{kg}$, ip $)$ or the morphine-associated cue-induced reinstatement was tested in the same animals. The dose of DSF or NEP was selected based on the acute drug effect and previous research [13, 14, 24] (Fig. 1).

Experiment 4: The effect of acute administration of DSF or NEP on reinstatement of drug-seeking behavior

Other cohorts of rats with extinguished self-administration and divide to separated groups (Fig. 1) were used in the reinstatement tests. The rats were subjected to acute pretreatment with DSF $(6.25-25 \mathrm{mg} / \mathrm{kg} ; n=10)$, NEP $(6.25-25 \mathrm{mg} / \mathrm{kg} ; n=10)$ or the corresponding vehicles 120 min prior to commencement of the reinstatement sessions. Only one reinstatement protocol was applied to each rat, involving either a morphine infusion $(5 \mathrm{mg} / \mathrm{kg}$, ip $)$ or presentation of a morphine-associated cue. A Latin square design was employed to set the injection order. Each animal received a drug combination in a randomized order in three to four reinstatement tests. Two to three extinction sessions at the minimum were run to separate each test session (Fig. 1).

\section{Locomotor activity}

The locomotor activity was recorded in Opto-Varimex cages (Columbus Instruments, Columbus, OH, USA) as described previously $[25,26]$. Separate groups of naive rats were tested for the effect of acute or repeated (14 days) administration of DSF $(6.25-50 \mathrm{mg} / \mathrm{kg}, n=5-7$ rats/groups) or NEP $(6.25-50 \mathrm{mg} / \mathrm{kg}, n=7-10 \mathrm{rats} / \mathrm{groups})$ on locomotor activation. The naive rats were habituated 2 days $/ 45 \mathrm{~min}$ before the administration of the drug. On the test day, animals were put into experimental cages and the locomotor activity was recorded for $120 \mathrm{~min}$.

\section{Biochemical analyses}

\section{Surgical procedures}

Guide cannulae (MAB 4; AgnTho's, Stockholm, Sweden) aimed at the nucleus accumbens, including the shell and core [anteroposterior: $+1.7 \mathrm{~mm}$; mediolateral: $+1.0 \mathrm{~mm}$; dorsoventral: $-5.8 \mathrm{~mm}$ ] [27], were stereotaxically implanted as described previously [28]. To fix the guide cannulae to the rat skull, two miniature stainless steel screws and dental acrylic cement were used. Additionally, the guide cannulae was protected by obturators, which were maintained till the microdialysis test. After the surgery, all rats were allowed an 8-day recovery period.

\section{Microdialysis procedures}

On the test day, microdialysis probes (MAB 4, membrane with a molecular weight 6-kDa cut-off, 2-mm length, 0.24mm outer diameter, AgnTho's AB, Lidingö, Sweden) were inserted into the guide cannulae (with the active membrane of internal cannulae extending $2 \mathrm{~mm}$ beyond the end of the guide cannulae) after obturator removal. Rats were then put into the experimental chambers and probes were connected to the liquid swivel (Instech, Plymouth Meeting, PA, USA) mounted on a counterbalanced arm at the top of a chamber and connected by polyethylene tubing (OD $0.68-\mathrm{mm}$; AgnTho's) to a microinfusion pump (CMA/Microdialysis, Dalvägen, Sweden). Microdialysis probes were perfused with an artificial cerebrospinal fluid (in $\mathrm{mM}: \mathrm{NaCl} 147$, $\mathrm{KCl} 4.0, \mathrm{MgCl}_{2}$ 1.0 $\mathrm{CaCl}_{2} 2.2, \mathrm{pH}$ 7.4) at a constant flow rate $(2 \mu \mathrm{l} / \mathrm{minute})$. The collection of dialysate samples commenced $80 \mathrm{~min}$ after the onset of perfusion to achieve stable dialysis neurotransmitters levels and perfusates. Following the collection of four dialysate samples (every 24 min thereafter, time period from -96 to $0 \mathrm{~min}$ ), used to determine spontaneous neurotransmitter levels (i.e. baseline samples), subsequent five samples were collected during the 2-hour session (time period from 0 to $120 \mathrm{~min}$ ). All the samples were immediately frozen and stored at $-20^{\circ} \mathrm{C}$ until the later determination of extracellular neurotransmitter levels. DSF $(12.5-50 \mathrm{mg} / \mathrm{kg} ; n=4-7), \mathrm{NEP}(12.5-25 \mathrm{mg} / \mathrm{kg} ; n=4-6)$ and the corresponding vehicles $(n=7-9)$ were administered acutely during the microdialysis test or for 13 sequential days before and once during the microdialysis test (14 days of administration in total).

\section{Measurement of dopamine and its metabolites}

The levels of extracellular dopamine, 3,4-dihydroxyphenylacetic acid (DOPAC) and homovanillic acid (HVA) in $10 \mathrm{uL}$ dialysate were assessed by ultra-high-performance liquid chromatography (UHPLC) with coulochemical detection. The UHPLC Ultimate 3000 system Dionex (Thermo Scientific, Germering, Germany) was equipped with an ECD-3000 RS electrochemical detector, 6011 RS ultra coulometric analytical cell, WPS-3000 RS autosampler and Hypersil Gold analytical column $3 \mu \mathrm{m}, 100 \times 3 \mathrm{~mm}$ (Thermo Scientific, Waltham, MA, USA). The mobile phase consisted of $0.1 \mathrm{M}$ $\mathrm{KH}_{2} \mathrm{PO}_{4}, 0.5 \mathrm{mM}$ EDTA, $80 \mathrm{mg} / 1$ sodium 1-octanosulfonate and $4 \%$ methanol; adjusted to $\mathrm{pH}=4.0$ with $85 \% \mathrm{H}_{3} \mathrm{PO}_{4}$. The flow rate of $0.6 \mathrm{ml} / \mathrm{min}$ and the column temperature of $30{ }^{\circ} \mathrm{C}$ were applied. The potentials of coulometric cell were: $\mathrm{E} 1=-50 \mathrm{mV}, \mathrm{E} 2=+350 \mathrm{mV}$. The external standard consisted of dopamine and DOPAC at concentrations of 
$50 \mathrm{ng} / \mathrm{ml}$ and HVA at a concentration of $100 \mathrm{ng} / \mathrm{ml}$ (Sigma). The chromatographic peaks were identified and quantized by comparison with the reference standard peaks. The Dionex Chromoleon 7 software (Thermo Scientific, Waltham, MA, USA) was used for data collection and analysis. The values were not corrected for in vitro probe recovery that amounted to approximately $15 \%$. The limit of detection of dopamine, DOPAC and HVA was $0.5 \mathrm{pg} / 10 \mu \mathrm{L}$.

\section{Histology}

Immediately after the completion of the microdialysis experiment, rats were overdosed with sodium pentobarbital (morbital; $133.3 \mathrm{mg} / \mathrm{ml}$; ip; Biowet, Puławy, Poland) and the brains were removed and stored in a $4 \%$ paraformalin (VWR Chemicals, Leuven, Belgium) solution for at least 3 days. Brains were cut on a cryostat and mounted on gel-coated glass slides. The placements of microdialysis probes were verified using a light microscope (PZO, Warszawa, Poland). Only data from rats with correctly placed probes within the nucleus accumbens, according to previously established guidelines, were included in statistical analyses. There was no necrosis distal to the track upon histological examination of the sections.

\section{Statistical analysis}

In the case of all behavioral experiments, the data are represented as the means $( \pm$ SEM). Experiment 1: during morphine self-administration and extinction training, the number of responses on the active and inactive levers was analyzed via a two-way repeated measures ANOVA with the factors lever (an active or inactive lever) and session as the repeated measure, or in the case of cue- or drug-reinstatement seeking behavior by a two-way ANOVA for factors lever (an active or inactive lever) and phases (self-administration, extinction and reinstatement of seeking behavior), respectively. Experiment 2: the effect of acute administration of DSF or NEP on morphine self-administration was analyzed by a one-way ANOVA for number of morphine infusions or a two-way ANOVA for factors pretreatment $\times$ lever. Experiment 3: the effect of repeated drug administration during extinction training and reinstatement seeking behavior was assessed using a three-way repeated measures ANOVA with the factors pretreatment $\times$ lever $\times$ session, and a three-way ANOVA for the pretreatment $\times$ reinstatement $\times$ lever interaction. Experiment 4: the effects of acute administration of DBH inhibitors on the reinstatement of seeking behavior were analyzed using a two-way ANOVA with factors phases $\times$ lever or pretreatment $\times$ lever. In experiments $1-4$ (see above), post hoc comparisons were performed using a Newman-Keuls' test for the significant effects identified by ANOVAs. Data for total locomotor activity were analyzed using a Student's unpaired $t$-test, two-tailed for repeated administration, or one-way ANOVA with Dunnett's post hoc for acute administration.

The results of the biochemical experiment were analyzed using a Student's unpaired $t$-test, two-tailed for the basal level of dopamine and its metabolites or a two-way repeated measures ANOVA with pretreatment $\times$ session factors for the effect of acute or repeated administration of DSF or NEP.

Analyses in each behavioral and biochemical experiments were performed using the Statistica v.13 software (StatSoft Polska, Kraków, Polska). $p<0.05$ was considered statistically significant. Graphs/figures were produced using the SigmaPlot v.12 and v.14 (Systat Software, San Jose, CA, USA) or GraphPad Prisma v. 8.1.1. (GraphPad Sofware Inc., La Jolla, CA, USA) software.

\section{Results}

\section{Morphine self-administration and reinstatement of drug-seeking}

In all experiments, rats acquired morphine self-administration and showed stable responses on the levers during the last three self-administration maintenance sessions with an acquisition criterion allowing variation in the number of active presses amounting to less than $15 \%$.

\section{Morphine self-administration (Experiment 1)}

As demonstrated in Fig. 2A, during 22-day self-administration, the number of active lever-responses increased between consecutive sessions, and when saline was substituted for morphine, a progressive drop in lever responses was seen over 15-day extinction training. A two-way ANOVA for repeated measures indicated a significant effect for the session $\left[F_{36,648}=24.70, p=0.00002\right]$, lever $\left[F_{2,18}=243.49\right.$, $p=0.00002]$ and session $\times$ lever interaction $\left[F_{36,648}=16.41\right.$, $p=0.00002]$, while the Newman-Keuls' post hoc analyses revealed that rats responded more on the active lever than the inactive lever from the 3rd till 29th (7th extinction) experimental day. The total quantity of morphine taken by rats during 22-day morphine self-administration was $102.74 \pm 4.77 \mathrm{mg} / \mathrm{rat}$, with a daily number of infusions during the last 3 sessions of maintenance of morphine self-administration in two trained groups ranging between $11.7 \pm 0.40$ and $12.60 \pm 0.54$. Similar results were observed for experiments (2-4) of morphine self-administration. 
Fig. 2 Morphine $(0.56 \mathrm{mg} / \mathrm{kg} /$ infusion) self-administration (SA) under increasing schedule of reinforcement (FR1-5), extinction training (EXT) (panel $\mathbf{A}$ and $\mathbf{B}$ ) and reinstatement seeking-behavior induced by a conditional stimulus associated previously with drug-taking (CUE; light + tones) and a non-conditional (morphine $2.5-10 \mathrm{mg} / \mathrm{kg}$, ip) (panel B stimulus in rats. The number of active, inactive lever responses and infusions are expressed as means $( \pm$ SEM $)$ of data from 7 to 10 rats/group (the number of rats on the graph). The results were evaluated statistically using a two-way ANOVA with or without repeated measures, with Newman-Keuls' post hoc. $* * * p<0.001$ versus SA-active lever; ${ }^{\wedge} p<0.01,{ }^{\wedge \wedge \wedge} p<0.001$ versus EXT-active lever
A
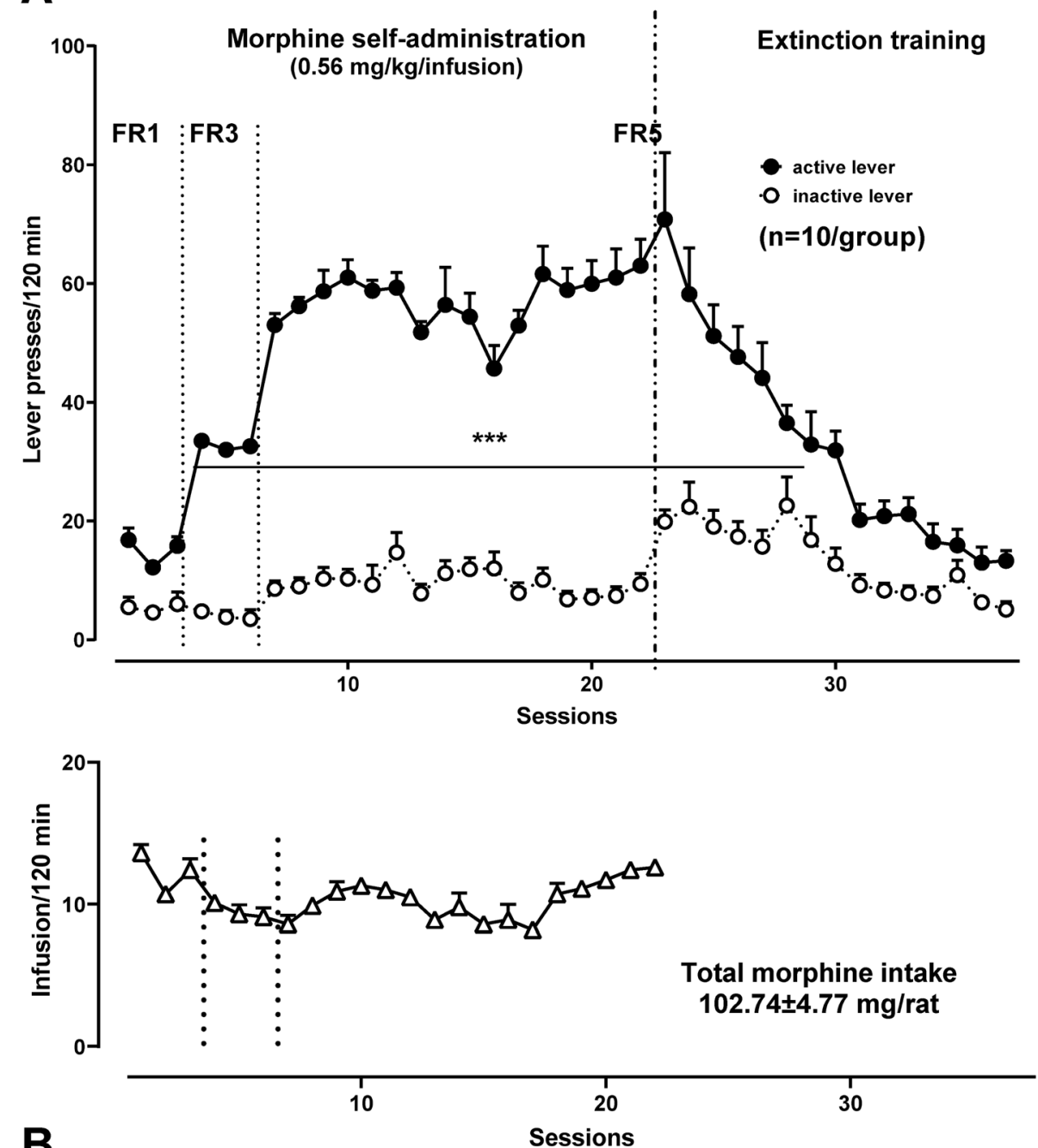

B

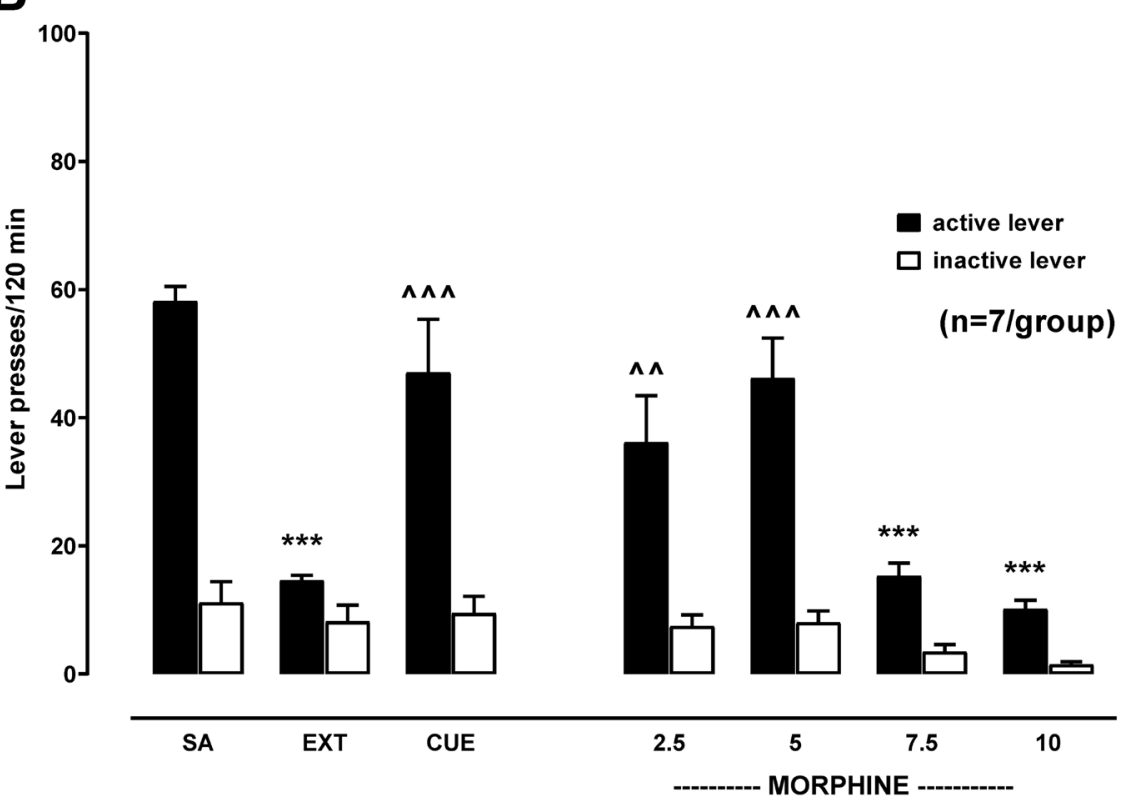




\section{Morphine and morphine-associated cue reinstatement of seeking behavior (Experiment 1)}

Reinstatement of seeking behavior induced by a cue or treatment with morphine $(2.5-10 \mathrm{mg} / \mathrm{kg}$ ) given before the start of the test session resulted in changes in the number of leverresponses (Fig. 2B).

A two-way ANOVA indicated a significant effect for the reinstatement (cue) $\left[F_{2,36}=7.82, p=0.0015\right]$, lever $\left[F_{1,36}=50.09, p=0.0002\right]$ and reinstatement $($ cue $) \times$ lever interaction $\left[F_{2,36}=3.71, p=0.0342\right]$. Reinstatement of seeking behavior induced by a cue associated with morphine self-administration increased of active lever-responses $(p<0.001)$, without changes in inactive lever-responses between experimental phases.
Treatment with morphine induced a significant effect for the reinstatement (drug) $\left[F_{5,72}=15.81, p=0.0002\right]$, lever $\left[F_{1,72}=106.00, p=0.0002\right]$ and reinstatement (drug) $\times$ lever interaction $\left[F_{5,72}=5.55, p=0.0002\right]$ in rats that underwent morphine self-administration and extinction training. A Newman-Keuls' post hoc test indicated significant increases of active lever-responses in the extinguished rats treated with the doses of 2.5 and $5 \mathrm{mg} / \mathrm{kg}(p<0.01$ and 0.001 , respectively).

\section{The effect of acute treatment with DSF or NEP on morphine self-administration (Experiment 2)}

The effects of acute administration of DSF (12.5-50 mg/ $\mathrm{kg})$ and NEP $(12.5-50 \mathrm{mg} / \mathrm{kg})$ on active and inactive lever

\section{Disulfiram}
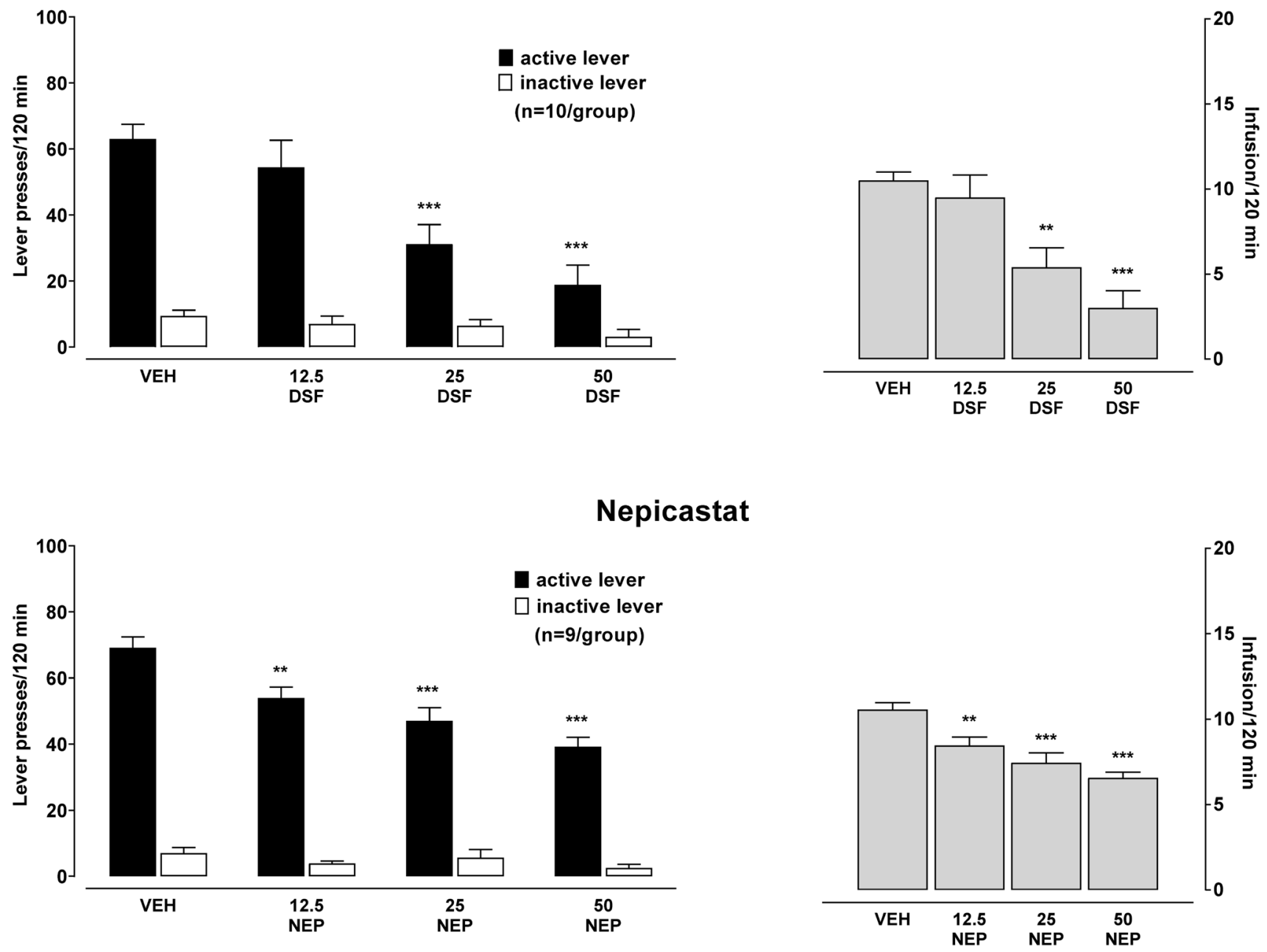

Fig. 3 The effect of acute pre-treatment with disulfiram (DSF, 12.5$50 \mathrm{mg} / \mathrm{kg}$, ip, top panel), or nepicastat (NEP, $12.5-50 \mathrm{mg} / \mathrm{kg}$, ip, bottom panel) or the corresponding vehicle (VEH) on active and inactive lever responses and on infusion during morphine $(0.56 \mathrm{mg} / \mathrm{kg} /$ infusion) self-administration in rats. All bars represent the means
$( \pm$ SEM) of the data from 8 to 9 rats/group the (number of rats above bar). The results were evaluated statistically using a one- or two-way ANOVA with Newman-Keuls' post hoc. ${ }^{* *} p<0.01$, ***p $p 0.001$ versus VEH-active lever or VEH 
presses and the number of morphine infusions are shown in Fig. 3. A two-way ANOVA revealed significant effects for the pretreatment $\times$ lever interaction for DSF and NEP $\left[F_{3,72}=7.47, p=0.0002\right.$ and $F_{3,64}=8.91, p=0.00005$, respectively]. The number of active lever-responses for morphine administration was suppressed in the rats treated with 25 and $50 \mathrm{mg} / \mathrm{kg}$ of DSF $(p<0.001)$ and with all used doses of NEP ( $p p<0.01-0.001)$. Treatment with DSF or NEP given acutely before the start of the test session resulted in a dose-related reduction in the number of morphine infusions [a one-way ANOVA: $F_{3,36}=11.29, p=0.00002$ and $\left.F_{3,32}=13.55, p=0.00001\right]$. A Newman-Keuls' post hoc test indicated a significant reduction in the number of infusions in the rats treated with 25 and $50 \mathrm{mg} / \mathrm{kg}$ DSF $(p<0.01-0.001)$ and $12.5-50 \mathrm{mg} / \mathrm{kg} \mathrm{NEP}(p<0.01-0.001)$.

\section{The effect of repeated administration of DSF or NEP on extinction training and reinstatement of drug-seeking behavior (Experiment 3)}

After 21 days of morphine self-administration, an extinction training was introduced to all animals, without the drug or a drug-associated cue.

A three-way ANOVA did not indicate any effect for the session $\times$ pretreatment $\times$ lever interaction $\left[F_{13,442}=1.43\right.$, $p=0.1401$ and $\left.F_{13,338}=0.95, p=0.5044\right]$ between groups that underwent repeated administration of vehicle, DSF $(50 \mathrm{mg} / \mathrm{kg})$ or NEP $(25 \mathrm{mg} / \mathrm{kg})$ (Fig. 4B) and during extinction training the reduction in active lever presses was observed $(p<0.001)$, as compared to the last morphine selfadministration session in all experimental groups (Fig. 4).

\section{Reinstatement of cue-induced seeking behavior After} 14-daily administration of vehicle or DSF $(50 \mathrm{mg} / \mathrm{kg})$, during the extinction-training period, rats were tested for the response reinstatement induced by a morphine-associated cue (Fig. 4C). As shown by a three-way ANOVA for the pretreatment $\times$ reinstatement (cue) $\times$ lever interaction $\left[F_{2,100}=0.32, p=0.7266\right]$, reinstatement of seeking behavior induced by a cue was relevant following either vehicle or DSF pretreatment (at least $p<0.05$ ), but did not reveal a significant difference between groups treated with vehicle or DSF, suggesting that rats responded similarly to the cue. However, during the cue-induced reinstatement in rats treated with DSF attenuation of active lever-responses compared to the control group ( $p=0.0573$ ) was observed.

Similarly, a three-way ANOVA for the pretreatment $\times$ reinstatement (cue) $\times$ lever interaction $\left[F_{2,78}=2.76\right.$, $p=0.0695]$ did not indicate a significant effect of the repeated administration of vehicle or NEP $(25 \mathrm{mg} / \mathrm{kg})$ during the extinction training. Further, the cue-induced reinstatement was similar (at least $p<0.05$ ) (Fig. 4). However, an analysis of active lever presses during reinstatement of seeking behavior revealed attenuation of active leverresponses in animals treated with NEP, respectively $(p=0.0580)$.

Reinstatement of morphine-induced seeking behavior A three-way ANOVA for factors pretreatment, reinstatement (drug), and lever demonstrated that repeated treatment with DSF $(50 \mathrm{mg} / \mathrm{kg})$ or NEP $(25 \mathrm{mg} / \mathrm{kg})$ during extinction training did not change increased lever presses (at least $p<0.01$ ) noted during reinstatement $\left[F_{3,120}=0.002, p=0.9999\right.$ and $F_{3,100}=0.27, p=0.8450$, respectively] (Fig. 2E, F).

\section{The effect of acute administration of DSF or NEP on reinstatement of morphine-seeking behavior (Experiment 5)}

Reinstatement of cue-induced seeking behavior: The 14-day extinction training led to the reduction in active lever presses $(p<0.001)$, more than inactive lever presses, compared to the last morphine self-administration session in both experimental groups [a two-way ANOVA: $F_{1,36}=19.47$, $p=0.0001$ and $\left.F_{1,36}=27.93, p=0.0001\right]$ (Fig. 5C).

Regarding the cue-induced seeking behavior, measured as increases of active lever-responses $(p<0.001)$, a twoway ANOVA revealed an effect for the cue-induced reinstatement of seeking behavior in both experimental groups $\left[F_{1,36}=9.06, p=0.0048\right.$ and $\left.F_{1,36}=7.93, p=0.0078\right]$ (Fig. 5A, C).

When DSF $(6.25-25 \mathrm{mg} / \mathrm{kg}$ ) was administered $2 \mathrm{~h}$ before placing rats in the experimental cage, a marked reduction in the number of active lever-responses induced by the cue was observed [a two-way ANOVA: $\left.F_{3,72}=4.26, p=0.0079\right]$ ]. A Newman-Keuls' post hoc test demonstrated a reduction in active lever presses in rats treated with all used doses of DSF $(p<0.001)$ (Fig. 5A), in comparison to vehicle-treated rats.

Similarly, treatment with NEP $(6.25-25 \mathrm{mg} / \mathrm{kg})$ reduced the cue-induced reinstatement. A two-way ANOVA indicated a significant effect for the pretreatment $\times$ lever interaction $\left[F_{3,72}=3.94, p=0.0116\right]$. A Newman-Keuls' post hoc test indicated decreases in active lever responses $(p<0.001)$ for all used doses of NEP during the reinstatement of seeking behavior induced by a morphine-associated cue (Fig. 5C).

\section{Reinstatement of the drug-induced seeking behavior}

All rats were extinguished after 14-day experimental procedure [a two-way ANOVA: $F_{1,32}=52.06, p<0.0000$ and $\left.F_{1,32}=100.91, p<0.0000\right]$, and a significant reduction of the active lever-presses $(p<0.001)$ during the last session of extinction training compared to the last session of morphine self-administration was indicated (Fig. 5B, D).

The administration of morphine $(5 \mathrm{mg} / \mathrm{kg})$ reinstated rats' drug-seeking behaviors in both experimental groups [a 
A

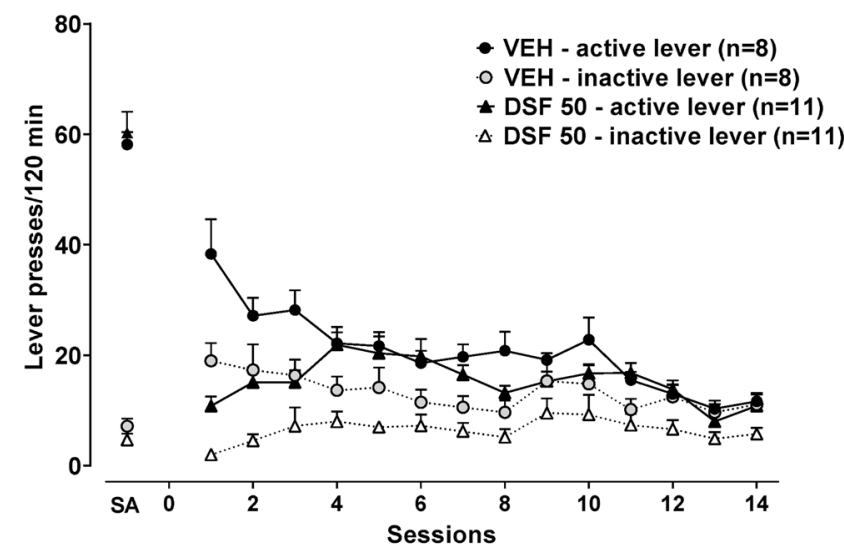

C

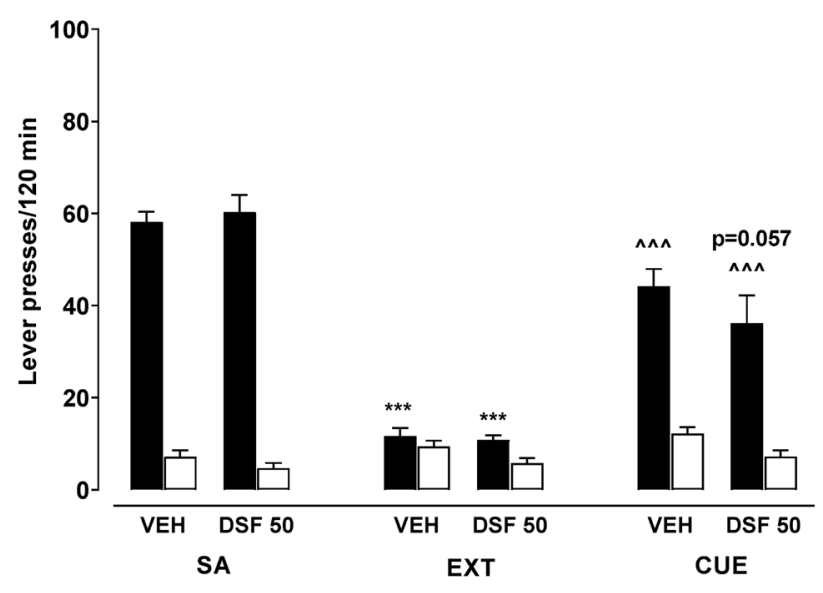

E

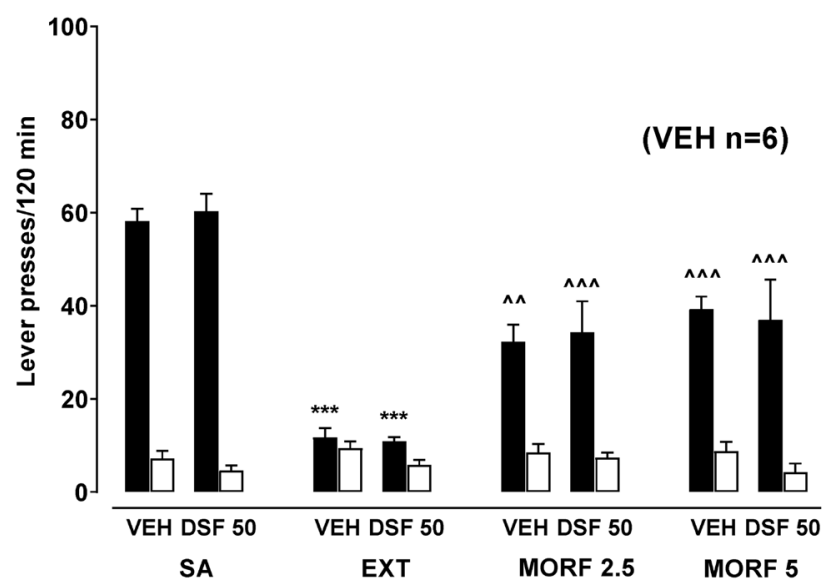

B

Nepicastat
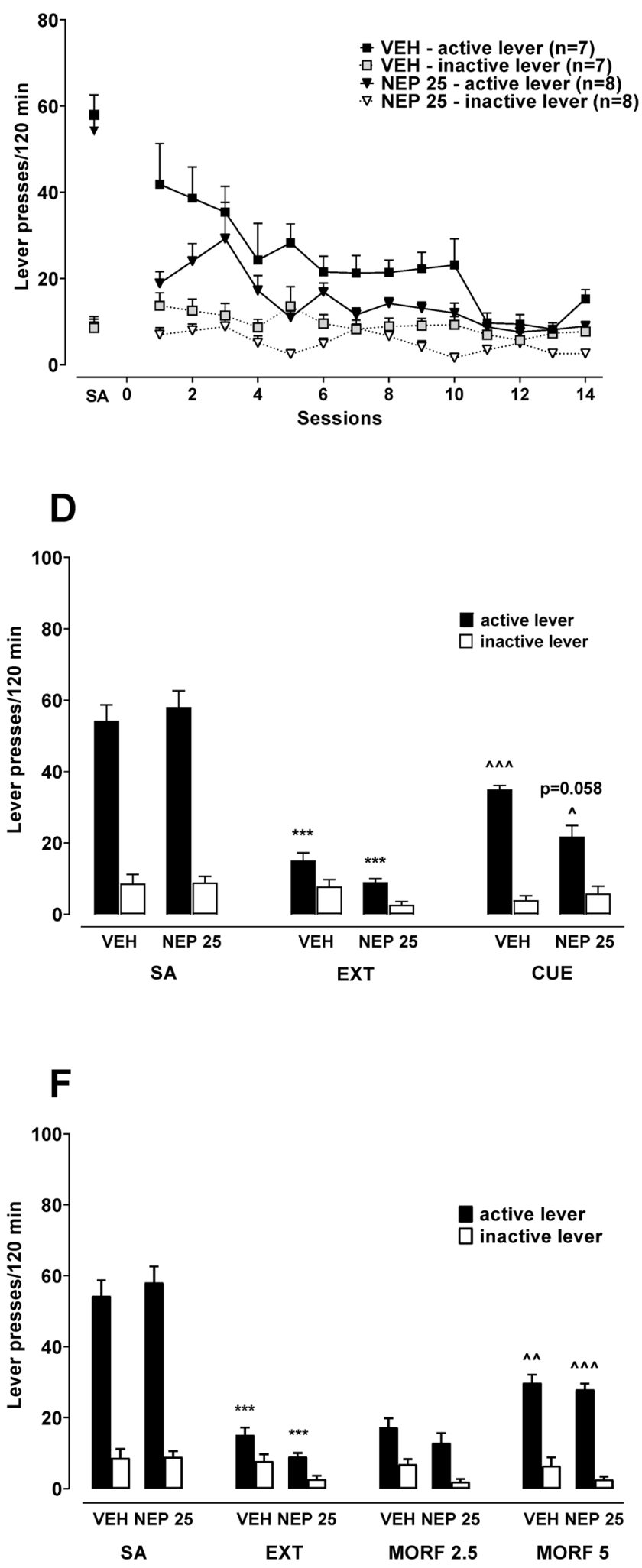
4Fig. 4 The effect of repeated pre-treatment with disulfiram (DSF, $50 \mathrm{mg} / \mathrm{kg}$, ip, panel A), nepicastat (NEP, $25 \mathrm{mg} / \mathrm{kg}$, ip, panel B) or the corresponding vehicle (VEH) on active and inactive lever responses during extinction training (EXT) in rats previously selfadministering morphine (SA) and their effect on reinstatement seeking-behavior induced by a conditional stimulus associated previously with drug-taking (CUE; light + tones, C, D) and a non-conditional (morphine $2.5-5 \mathrm{mg} / \mathrm{kg}$, ip, E, F) stimulus in rats. All bars represent the means $( \pm$ SEM) of the data from 7 to 11 rats/group (number of rats above bar). The results were evaluated statistically using a twoway repeated measures ANOVA with Newman-Keuls' post hoc. $* * * p<0.001$ versus corresponding SA group-active lever, ${ }^{\wedge} p<0.05$, ${ }^{\wedge} p<0.01,{ }^{\wedge \wedge \wedge} p<0.001$ versus corresponding EXT group-active lever

two-way ANOVA: $F_{1,32}=6.58, p=0.0152$ and $F_{1,32}=24.46$, $p=0.00002]$. The number of active lever-responses during the reinstatement session was raised substantially $(p<0.001)$ (Fig. 5B, D).

A two-way ANOVA indicated a significant effect of treatment with DSF $(6.25-25 \mathrm{mg} / \mathrm{kg})$ on the number of lever-responses during morphine-induced reinstatement $\left[F_{3,60}=3.73, p=0.0158\right]$. In fact, the number of active leverresponses was reduced in the rat groups treated with all used doses of DSF $(p<0.05-0.001)$ (Fig. 5B).

A reduction of reinstatement seeking behavior induced by re-treatment with morphine $(5 \mathrm{mg} / \mathrm{kg})$ was demonstrated after NEP $(6.25-25 \mathrm{mg} / \mathrm{kg}$ ) [a two-way ANOVA for factors pretreatment $\times$ lever: $\left.F_{3,56}=25.82, p<0.0000\right]$. A post hoc test revealed a marked reduction in the active lever presses in rats treated with all doses of NEP $(p<0.001)$ (Fig. 5D).

\section{Locomotor activity}

When DSF or NEP was administered acutely $2 \mathrm{~h}$ before transferring naive rats into the locomotor activity cage, it produced a marked change in locomotor activity $\left[F_{4,25}=8.52 ; p=0.0002\right.$ and $F_{4,34}=5.84 ; p=0.0011$, respectively] (Fig. 6C). In comparison to vehicle-treated rats, the distanced traveled was reduced by ca. $65 \%$ in rats given $50 \mathrm{mg} / \mathrm{kg}$ of either DSF or NEP. Similarly, a reduction by ca. $45 \%$ and $36 \%\left[t_{10}=2.41 ; p=0.0364\right.$ and $t_{14}=2.53$; $p=0.0241]$ in locomotor activity was recorded after repeated (14 days) treatment with $50 \mathrm{mg} / \mathrm{kg}$ DSF or $25 \mathrm{mg} / \mathrm{kg}$ NEP (Fig. 6B, D).

\section{The effect of acute and repeated administration of DSF or NEP on the extracellular level of dopamine and its metabolites in the nucleus accumbens}

After the surgery and recovery period, the rats experimentally naïve were tested to measure variations in the level of extracellular dopamine and its metabolites, DOPAC and HVA using microdialysis in the nucleus accumbens (Table 1 and Fig. 7).
DSF administered at a dose of $50 \mathrm{mg} / \mathrm{kg} i p$ for 13 days resulted in a reduction (and a tendency to decrease) basal concentration of dopamine and DOPAC (down to 38\% and $32 \%$ of the vehicle, respectively), but not HVA compared to the corresponding vehicle (Table 1). Repeated injections of DSF did not significantly affect the DOPAC/DA ratio, but significantly increased the HVA/DA ratio (up to $208 \%$ vehicle value).

Pretreatment with NEP at a dose of $25 \mathrm{mg} / \mathrm{kg}$ ip for 13 days decreased the basal concentrations of dopamine and DOPAC (down to $45 \%$ and $72 \%$, respectively), and lacked any significant impact on the DOPAC/DA ratio. The HVA level remained unchanged, however, the HVA/DA ratio measured in the tested structure was significantly increased (up to $196 \%$ of the vehicle) (Table 1).

A two-way repeated measures ANOVA did not indicate any significant effect of acute DSF treatment with doses of 12.5 and $50 \mathrm{mg} / \mathrm{kg}$ on factors: pretreatment $\times$ session for any of the measured parameters, dopamine, DOPAC and HVA $\left[F_{10,80}=0.93, p=0.5103 ; F_{10,80}=0.22, p=0.9933\right.$; $F_{10,80}=0.42, p=0.9282$, respectively] (Fig. 7A-C).

The repeated treatment with DSF at a dose of $50 \mathrm{mg} /$ $\mathrm{kg}$ did not significantly change the dopamine level during microdialysis [pretreatment $\times$ session interaction: $\left.F_{5,45}=2.01, p=0.0948\right]$ (Fig. 7A). A reduction in dopamine level was observed during that time but the overall analysis indicated that this effect was insignificant. Instead, a repeated measures ANOVA revealed a significant difference in the level of DOPAC and HVA $\left[F_{5,45}=3.11, p=0.0170\right.$; $F_{5,45}=3.27, p=0.0132$, respectively]. A Newman-Keuls' post hoc test demonstrated a reduction of the DOPAC level compared to the corresponding vehicle $(p<0.05-0.001)$ and basal level $(p<0.001)$ (Fig. 7B). Similarly, a Newman-Keuls' post hoc test performed for the HVA level indicated a reduction for the repeated DSF administration $(p<0.01)$ between the first and last measurement (Fig. 7C).

Acute administration of NEP at doses of 12.5 and $25 \mathrm{mg} /$ $\mathrm{kg}$ during microdialysis test session did not change the dopamine, DOPAC or HVA levels $\left[F_{10,85}=1.52, p=0.1462\right.$; $F_{10,85}=1.63, p=0.1133 ; F_{10,85}=1.17, p=0.3207$, respectively] (Fig. 7D-F).

Similarly, a repeated measures ANOVA did not indicate any significant effect of repeated administration of NEP in a dose of $25 \mathrm{mg} / \mathrm{kg}$ on the measured parameters during microdialysis: dopamine, DOPAC and HVA $\left[F_{5,55}=1.75\right.$, $p=0.1384 ; F_{5,55}=1.52, p=0.1999 ; F_{5,55}=1.53, p=0.1949$, respectively] (Fig. 7D-F). 


\section{Disulfiram}

A

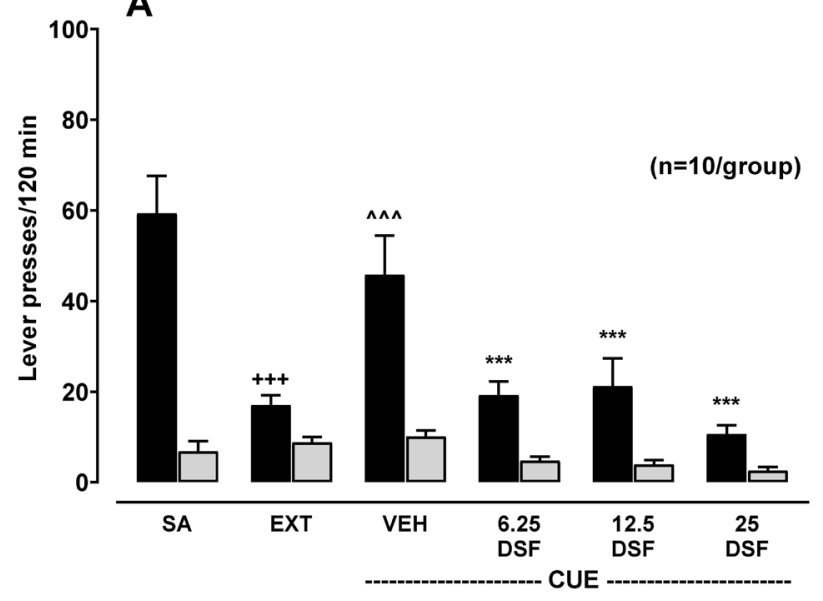

B

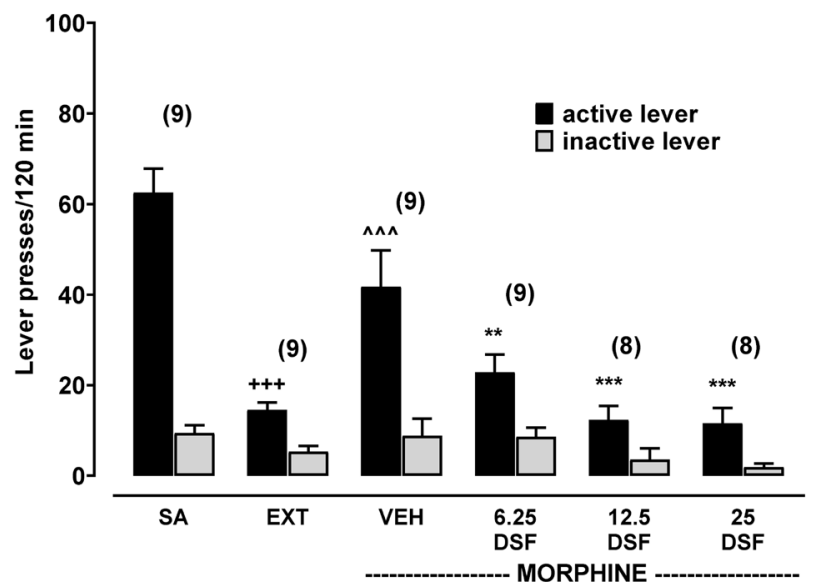

\section{Nepicastat}

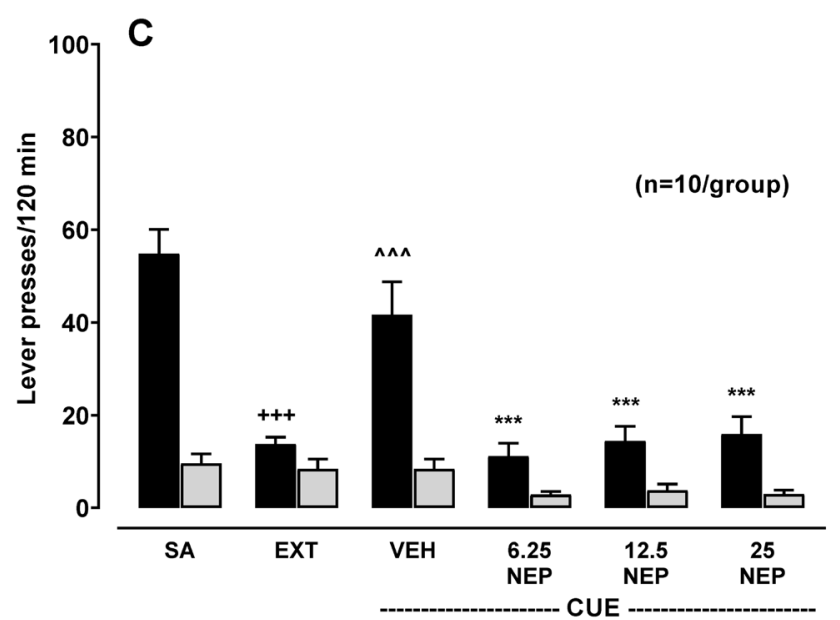

Fig. 5 The effect of acute pre-treatment with disulfiram (DSF, 6.25$25 \mathrm{mg} / \mathrm{kg}$, ip, panels A, B), nepicastat (NEP, 6.25-25 mg/kg, ip, panels $\mathbf{C}, \mathbf{D})$ or the corresponding vehicle $(\mathrm{VEH})$ on active and inactive lever responses on reinstatement seeking-behavior induced by a conditional stimulus associated previously with drug-taking (CUE; light + tones) and a non-conditional (morphine $5 \mathrm{mg} / \mathrm{kg}$, ip) stimu-

\section{Discussion}

\section{Morphine self-administration, extinction training, and reinstatement of the drug-seeking behavior}

In the present study during the 22-day period of morphine self-administration, the animals maintained a stable level of morphine intake (ca. $6 \mathrm{mg}$ of the drug in the last session of self-administration). Replacing morphine with saline caused a robust reduction of active lever presses, which was extinguished after 14 days of exposure to the experimental cage during extinction training sessions. The presented data

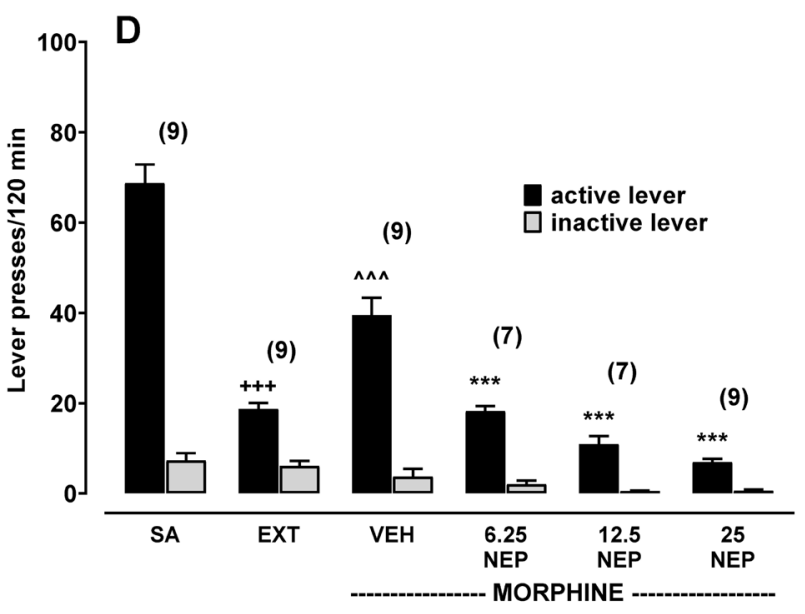

lus in extinguished (EXT) to morphine self-administrating (SA) rats. All bars represent the means $( \pm$ SEM) of the data from 7 to 10 rats/ group (number of rats above bar). The results were evaluated statistically using a two-way ANOVA with Newman-Keuls' post hoc. $+++p<0.001$ versus SA-active lever; ${ }^{\wedge \wedge} p<0.001$ versus EXTactive lever, $* * p<0.01, * * * p<0.001$ versus $\mathrm{VEH}$

confirm earlier reports that morphine can serve as a positive reinforcer in rats, and the pattern lever presses during maintenance of self-administration and extinction training stayed in line with a previous study [29-36].

Reinstatement of seeking-behavior in an animal model has been consistently described in the literature as a representative model of the propensity to relapse in humans [37]. Presentation of a conditional stimulus previously associated with morphine self-administration and a nonconditional stimulus (morphine, ip) resulted in relevant changes in lever presses in rats with extinguished seekingbehavior. Reinforcement behavioral reaction was related to an increase of active lever presses, but not inactive, 
Fig. 6 The effect of acute $(\mathbf{A}, \mathbf{C})$ and repeated $(\mathbf{B}, \mathbf{D})$ administration of disulfiram (6.25-50 mg/kg; ip, $\mathrm{n}=5-7)$ and nepicastat $(6.25-50 \mathrm{mg} /$ $\mathrm{kg}$; ip, $\mathrm{n}=7-10$ ) on locomotor activity (mean \pm SEM; number of rats above bar). $* p<0.05$, $* * * p<0.001$ versus 0 . The results were evaluated statistically using a Student's unpaired t-test, two-tailed or one-way ANOVA with Dunnett's post hoc
A

B

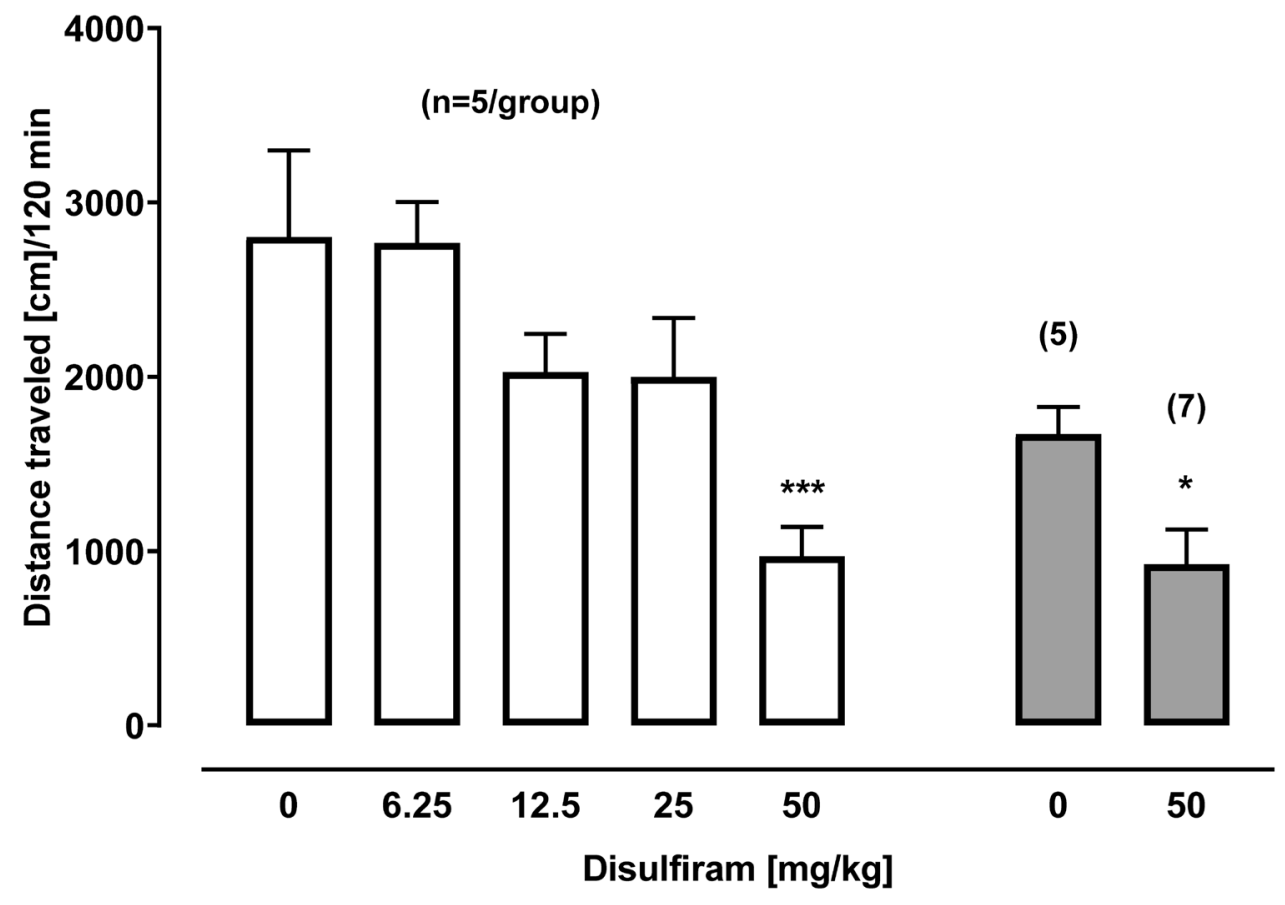

C

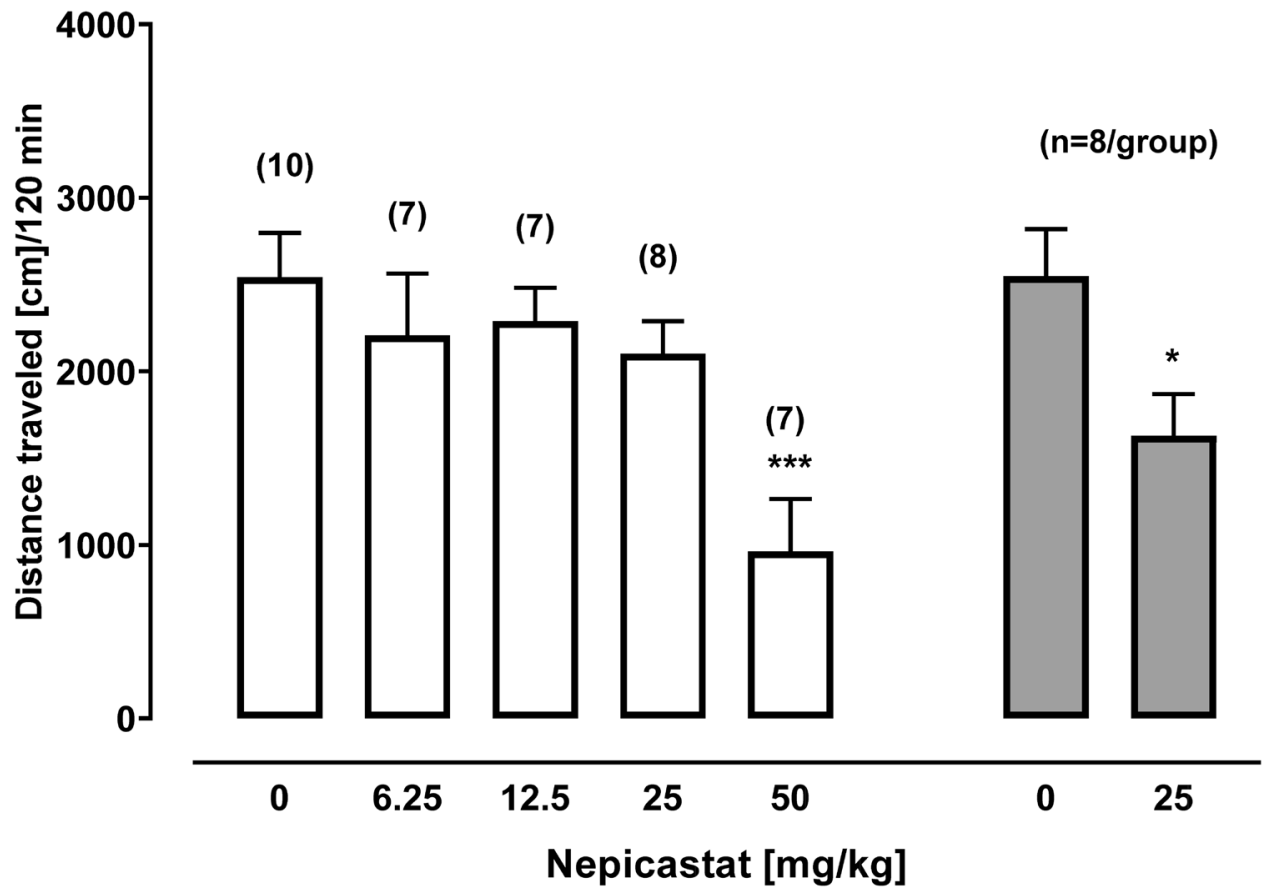

for both stimuli. During morphine-induced reinstatement, the active lever responses increased more markedly after exposure to doses 2.5 and $5 \mathrm{mg} / \mathrm{kg}$ than 7.5 and $10 \mathrm{mg} / \mathrm{kg}$. In the case of higher morphine doses, the lower active lever presses were associated with inactive lever presses (trend to reduce), which means that the behavioral response was sedation in general. Previous studies also show a robust rise in the number of responses reinforced by a conditional and non-conditional stimulus during reinstatement of seeking behavior [30, 32, 36, 38, 39]. 

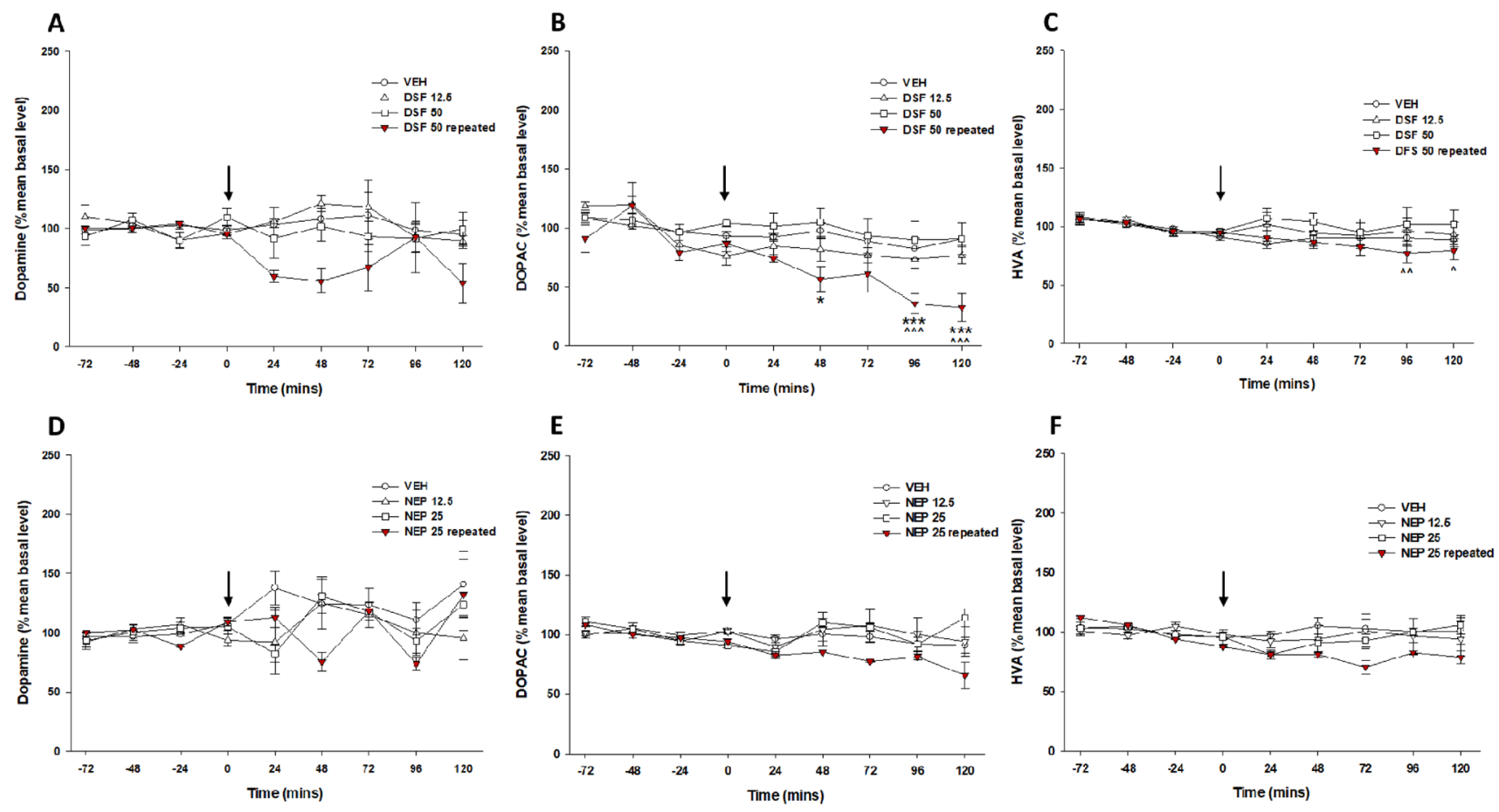

Fig. 7 The effect of acute and repeated pretreatment with disulfiram (DSF, $12.5-50 \mathrm{mg} / \mathrm{kg}$, ip, panels A-C) or nepicastat (NEP, 12.5$25 \mathrm{mg} / \mathrm{kg}$, ip; panels D-F) or the corresponding vehicle (VEH) on the extracellular dopamine and its metabolites DOPAC and HVA levels in the nucleus accumbens. Arrows represent administration of DSF,
NEP or VEH. Data are expressed as a percentage of mean basal level and shown as the mean \pm SEM of 4-9 rats. The results were evaluated statistically using a two-way repeated measures ANOVA with Newman-Keuls' post hoc. ${ }^{*} p<0.05, * * * p<0.001$ versus corresponding $\mathrm{VEH},{ }^{\wedge} p<0.05,{ }^{\wedge} p p<0.01,{ }^{\wedge \wedge \wedge} p<0.001$ versus $0 \mathrm{~min}$

Table 1 The effect of 13-day administration of disulfiram (DSF, $50 \mathrm{mg} / \mathrm{kg}$; ip, $n=4$ ), nepicastat (NEP, $25 \mathrm{mg} / \mathrm{kg}$; ip, $\mathrm{n}=4$ ) or the corresponding vehicle (VEH, ip, $n=7-9$ ) on the extracellular basal levels of dopamine (DA) and its metabolites, DOPAC and HVA, in the nucleus accumbens

\begin{tabular}{llllll}
\hline & DA $[\mathrm{pg} / 10 \mathrm{uL}]$ & DOPAC $[\mathrm{pg} / 10 \mathrm{uL}]$ & DOPAC/DA ratio & HVA [pg/10 uL] & HVA/DA ratio \\
\hline VEH & $3.89 \pm 1.14$ & $777.86 \pm 128.81$ & $256.91 \pm 49.13$ & $509.16 \pm 84.32$ & $177.70 \pm 42.25$ \\
DSF 50 mg/kg & $1.49 \pm 0.21$ & $248.31 \pm 35.70^{*}$ & $175.67 \pm 31.68$ & $525.75 \pm 71.21$ & $369.09 \pm 58.63 *$ \\
& $\mathrm{t} 9=1.54, \mathrm{p}=0.16$ & $\mathrm{t} 9=3.00, \mathrm{p}<0.05$ & $\mathrm{t} 9=1.15, \mathrm{p}=0.27$ & $\mathrm{t} 9=-0.13, \mathrm{p}=0.90$ & $\mathrm{t} 9=-2.69, \mathrm{p}<0.05$ \\
VEH & $2.69 \pm 0.44$ & $969.35 \pm 147,09$ & $396.62 \pm 45.81$ & $551,07 \pm 73,6$ & $252.08 \pm 48.44$ \\
NEP 25 mg/kg & $1.21 \pm 0.07$ & $701.54 \pm 93,54$ & $590.42 \pm 0.10$ & $591.41 \pm 90.57$ & $494.49 \pm 38.42 *$ \\
& $\mathrm{t} 11=2.16, \mathrm{p}=0.05$ & $\mathrm{t} 11=1.15, \mathrm{p}=0.28$ & $\mathrm{t} 11=-2.14, \mathrm{p}=0.06$ & $\mathrm{t} 11=-0.36, \mathrm{p}=0.72$ & $\mathrm{t} 11=-3.10, \mathrm{p}=<0.05$ \\
\hline
\end{tabular}

All data expressed the means $( \pm$ SEM) of the data from 4 to 9 rats/group. The results were evaluated statistically using a Student's unpaired t-test, two-tailed. *p $<0.05$ versus VEH

\section{The effect of acute or repeated treatment with DSF or NEP on morphine self-administration, extinction training, and reinstatement seeking behavior}

Another notable finding presented in the study is that both investigated DBH inhibitors reduced morphine intake and behavioral responses connected with active lever presses during self-administration of morphine in rats. Moreover, the present findings have shown that DSF and NEP administered acutely before the reinstatement test session consistently attenuated the reinforcing effects of morphine and a cue associated previously with drug-taking. However, 2-h pretreatment with DSF or NEP in the highest doses (50 mg/kg), markedly suppressed spontaneous locomotor activity, suggesting that these doses may have contributed, at least in part, to the suppressant effect of DBH inhibitors on morphine self-administration. Nevertheless, lower doses of DSF and NEP prior to morphine self-administration effectively reduced active lever-responding related to morphine reinforcement in rats. The above effects were specific as both DBH inhibitors neither changed locomotor activity when given alone to naïve rats nor altered the 
inactive lever pressing in the morphine self-administration model. In the study with repeated administration of DSF $(50 \mathrm{mg} / \mathrm{kg})$ and NEP $(25 \mathrm{mg} / \mathrm{kg})$, neither drug modified inactive lever presses during extinction training in morphineexposed rats and the reinstatement of seeking behavior was not changed, despite their potent reduction locomotor activity in naïve animals. So far available preclinical trials have focused only on psychostimulants and provide mixed support for the idea that DBH inhibitors show promise as a treatment for substance use disorder. Although cocaine and morphine have different pharmacological mechanisms of action, the repeated treatment of these drugs leads to a rise in dopamine levels and a reduction in basal glutamate levels in sub-cortical and/or cortical brain areas. Thus, early studies showed that DSF pretreatment suppresses psychostimulants-induced locomotor activity in rodents [40, 41]. Other studies did not confirm any positive effect of acute administration of DSF and NEP on responding to cocaine during the maintenance phase of self-administration under an FR1 schedule of responding [13], but DSF-at the limited range of doses-consistently attenuated the reinforcing effects of $d$-methamphetamine [42]. Nevertheless, both DBH inhibitors reduce breakpoint responding for cocaine on a progressive ratio schedule, thus suggest that $\mathrm{DBH}$ inhibition may selectively attenuate the positive reinforcing effects of psychostimulants under conditions that require high motivation [14]. Clinical research revealed that DBH inhibitors can result in a reduction of the positive subjective effects of several psychostimulants [43, 44]. Other previous research shows that two DBH inhibitors, DSF and NEP, administered acutely in rodent's attenuate reinstatement of cocaine-seeking induced by a drug-primed conditional cue, stress, or even yohimbine [13-15, 45]. Instead, Cooper and co-workers [46] reported that DSF failed to attenuate cocaine reinstatement in squirrel monkeys.

Neither DSF nor NEP administered for 14 days during extinction training influenced lever responding. In the reinstatement of drug-seeking behavior induced by a non-contingent stimulus procedure, intended to reproduce reinstatement in lever responses related previously with self-administration of morphine, controls, and animals chronically treated with DBH inhibitors was not different. Interestingly, reinstatement of drug-seeking behavior induced by a cue previously associated with the availability of the reward, demonstrated a trend to lower responses in groups that received repeated administration of DSF or NEP during the abstinence period.

The nucleus accumbens is involved in the reinstatement of drug-seeking behavior induced by conditional and non-conditional stimuli and its role is related to a dopamine release $[47,48]$. In addition, the nucleus accumbens is found to be involved in the extinction of conditioned behavior, thought to be a process of new and active learning $[49,50]$. The drugs of abuse induce a large release of dopamine in limbic areas, specifically in the nucleus causes feelings of pleasure. Consistently with previous observations, in control rats DSF and NEP administered acutely did not change the extracellular level of dopamine and its metabolites $2 \mathrm{~h}$ after treatment $[17,47]$. In the present study, repeated, but not single, administration of DSF or NEP for several days to rats tended to reduce the extracellular basal levels of dopamine and DOPAC suggesting a diminished release of dopamine in the synaptic cleft and/or augment dopamine reuptake. In fact, a significant increase in the accumbal HVA/DA ratio, without an effect on dopamine metabolite HVA was observed in rats. Dopamine is broken down into inactive metabolites by a set of enzymes. The major intracellular enzymes involved in neurotransmitter degradation are monoamine oxidases which convert dopamine into the intermediate metabolite 3,4-dihydroxyphenylacetaldehyde, and then into DOPAC. The other major enzyme related to extracellular dopamine metabolism is catechol-O-methyltransferase which transforms the neurotransmitter into 3-methoxytyramine (3-MT). Finally, both DOPAC and 3-MT are converted into HVA [51]. Because DBH inhibitors directly influenced the level of dopamine this mechanism might belong to DSF and NEP reduction of the reinforcing effects of abused drugs. As found, both DBH inhibitors reduced extracellular noradrenaline in the prefrontal cortex and nucleus accumbens [13-15, 20, 46, 52]. Anatomical and functional relationships between the noradrenergic, dopaminergic, and glutamatergic systems influence the sensitivity of the mesolimbic reward system to substance use disorder. Since norepinephrine stimulates the drive of dopamine neurons, both directly (via the ventral tegmental area) and indirectly (via glutaminergic projections from the prefrontal cortex to the ventral tegmental area) [53], inhibition of DBH would reduce the stimulation of dopamine neurons and the extracellular accumbal dopamine levels. Additionally, it is well documented the loss of norepinephrine in the prefrontal cortex also attenuates the drug-induced dopamine release in the nucleus accumbens $[44,53]$.

Major disadvantages of the presented microdialysis results are concerned with the doses of DBH inhibitors, which not fully correlated with behavioral experiments of morphine self-administration, and limiting data to only one brain structure, where drugs of abuse induce a large release of dopamine in several limbic areas not only in nucleus accumbens. However, based on these data, it might be timidly suggested that both DSF and NEP control behavioral responses by an inhibitory action on noradrenaline synthesis and release in the nucleus accumbens, while present data did not exclude their effect on dopamine metabolism and release. Moreover, an increased release of dopamine instead of noradrenaline from noradrenergic terminals in the prefrontal cortex cannot be ruled out. 


\section{Conclusions}

A major outcome of this study is that DSF and NEP reduced morphine self-administration and reinstatement of drug-seeking behavior induced by both conditional and non-conditional stimulus. Repeated administration of both DBH inhibitors admittedly did not influence the extinguished seeking behavior but attenuated reinstatement of seeking behavior induced by a stimulus previously associated with morphine taking. Moreover, this study has provided evidence that DBH inhibitors induced changes in behavioral responses related to morphine. These preclinical results point to a significance of DBH inhibition as a potential pharmacotherapy against morphine abuse, though limitations, such as the biochemical analysis of only one structure and focus on male sex, indicate a need for further studies to prove the beneficial potential of DBH inhibitors.

Some evidence from randomized controlled trials showed the effectiveness of DSF treatment in people with cocaine dependence and alcohol users toward fewer dropouts from psychosocial treatment, reduced cocaine positive urine toxicology screens and a greater number of weeks of abstinence $[12,44,52,54]$. Nevertheless, DSF has been founded to display poor effectiveness in opioid co-dependent subjects $[54,55]$. Furthermore, current clinical trials do not suggest the use of DBH inhibitors in the therapy of OUD or alcohol dependent subjects exhibiting comorbid opioid-related problems. It needs to be determined whether higher potency DBH inhibitors, such as NEP, are efficacious in reducing not only cocaine but also opioid use in dually cocaine and opioid dependent individuals.

Author contributions MF.: planned all behavioral and biochemical experiments, performed behavioral experiments and analyses, was involved in interpreting experimental data and wrote the manuscript. PS: performed behavioral experiments and analyses, was involved in interpreting experimental data and contributed to writing the final version of the manuscript; AS, RP: performed behavioral experiments; RP.: performed biochemical experiments; JJ: performed analyses, was involved in interpreting data from biochemical experiments, contributed to writing the final version of the manuscript; WAD: was involved in the analysis and interpreting data from biochemical experiments and participated in revising the article; MF: was involved in designing and supervising the research proposal, and interpreting data, contributed to writing the manuscript; MZ-B, PK: was involved in designing the research proposal and interpreting data, participated in revising the article.

Funding This research was financed from the grant no.: 2014/15/D/ NZ7/01821 assigned to Patrycja Kleczkowska by the National Science Centre (Kraków, Poland), and partially supported from the statutory funds of Maj Institute of Pharmacology, Polish Academy of Sciences (Kraków, Poland).

\section{Declarations}

Conflict of interest The authors declare that the research was conducted in the absence of any commercial or financial relationships that could be construed as a potential conflict of interest.

Open Access This article is licensed under a Creative Commons Attribution 4.0 International License, which permits use, sharing, adaptation, distribution and reproduction in any medium or format, as long as you give appropriate credit to the original author(s) and the source, provide a link to the Creative Commons licence, and indicate if changes were made. The images or other third party material in this article are included in the article's Creative Commons licence, unless indicated otherwise in a credit line to the material. If material is not included in the article's Creative Commons licence and your intended use is not permitted by statutory regulation or exceeds the permitted use, you will need to obtain permission directly from the copyright holder. To view a copy of this licence, visit http://creativecommons.org/licenses/by/4.0/.

\section{References}

1. UNODC, World Drug Report 2019, booklet 4; https://wdr.unodc. org/wdr20191.

2. EMCDDA,European Drug Report, Lisbon, September 2020 https://www.emcdda.europa.eu/system/files/publications/13238/ TD0420439ENN.pdf.

3. Nielsen S, Larance B, Degenhardt L, Gowing L, Kehler C, Lintzeris N. Opioid agonist treatment for pharmaceutical opioid dependent people. Cochrane Database Syst Rev. 2016(5):CD011117.

4. Koob GF, Volkow ND. Neurobiology of addiction: a neurocircuitry analysis. The lancet Psychiatry. 2016;3(8):760-73.

5. Di Chiara G, Imperato A. Drugs abused by humans preferentially increase synaptic dopamine concentrations in the mesolimbic system of freely moving rats. Proc Natl Acad Sci USA. 1988;85(14):5274-8.

6. Pierce RC, Kumaresan V. The mesolimbic dopamine system: the final common pathway for the reinforcing effect of drugs of abuse? Neurosci Biobehav Rev. 2006;30(2):215-38.

7. Olson VG, Heusner CL, Bland RJ, During MJ, Weinshenker D, Palmiter RD. Role of noradrenergic signaling by the nucleus tractus solitarius in mediating opiate reward. Science. 2006;311(5763):1017-20.

8. Davis WM, Smith SG. Catecholaminergic mechanisms of reinforcement: direct assessment by drug-self-administration. Life Sci. 1977;20(3):483-92.

9. Pozuelo J, Kerr FW. Suppression of craving and other signs of dependence in morphine-addicted monkeys by administration of alpha-methyl-para-tyrosine. Mayo Clin Proc. 1972;47(9):621-8.

10. Davis WM, Smith SG, Khalsa JH. Noradrenergic role in the self-administration of morphine or amphetamine. Pharmacol Biochem Behav. 1975;3(3):477-84.

11. Brown ZW, Amit Z, Sinyor D, Rockman GE, Ogren SO. Suppression of voluntary ingestion of morphine by inhibition of dopamine-beta-hydroxylase. Arch Int Pharmacodyn Ther. 1978;232(1):102-10.

12. George TP, Chawarski MC, Pakes J, Carroll KM, Kosten TR, Schottenfeld RS. Disulfiram versus placebo for cocaine dependence in buprenorphine-maintained subjects: a preliminary trial. Biol Psychiatry. 2000;47(12):1080-6.

13. Schroeder JP, Cooper DA, Schank JR, Lyle MA, GavalCruz M, Ogbonmwan YE, et al. Disulfiram attenuates 
drug-primed reinstatement of cocaine seeking via inhibition of dopamine beta-hydroxylase. Neuropsychopharmacology. 2010;35(12):2440-9.

14. Schroeder JP, Epps SA, Grice TW, Weinshenker D. The selective dopamine beta-hydroxylase inhibitor nepicastat attenuates multiple aspects of cocaine-seeking behavior. Neuropsychopharmacology. 2013;38(6):1032-8.

15. Devoto P, Fattore L, Antinori S, Saba P, Frau R, Fratta W, et al. Elevated dopamine in the medial prefrontal cortex suppresses cocaine seeking via D1 receptor overstimulation. Addict Biol. 2016;21(1):61-71.

16. Goldstein M, Anagnoste B, Lauber E, McKeregham MR. Inhibition of Dopamine-Beta-Hydroxylase by Disulfiram. Life Sci. 1962;1964(3):763-7.

17. Musacchio JM, Goldstein M, Anagnoste B, Poch G, Kopin IJ. Inhibition of dopamine-beta-hydroxylase by disulfiram in vivo. J Pharmacol Exp Ther. 1966;152(1):56-61.

18. Stanley WC, Li B, Bonhaus DW, Johnson LG, Lee K, Porter $\mathrm{S}$, et al. Catecholamine modulatory effects of nepicastat (RS25560-197), a novel, potent and selective inhibitor of dopamine-beta-hydroxylase. Br J Pharmacol. 1997;121(8):1803-9.

19. Bourdelat-Parks BN, Anderson GM, Donaldson ZR, Weiss JM, Bonsall RW, Emery MS, et al. Effects of dopamine beta-hydroxylase genotype and disulfiram inhibition on catecholamine homeostasis in mice. Psychopharmacology. 2005;183(1):72-80.

20. Devoto P, Flore G, Saba P, Cadeddu R, Gessa GL. Disulfiram stimulates dopamine release from noradrenergic terminals and potentiates cocaine-induced dopamine release in the prefrontal cortex. Psychopharmacology. 2012;219(4):1153-64.

21. Witkiewitz K, Vowles KE. Alcohol and Opioid Use, Co-Use, and Chronic Pain in the Context of the Opioid Epidemic: A Critical Review. Alcohol Clin Exp Res. 2018;42(3):478-88.

22. Bell J, Strang J. Medication treatment of opioid use disorder. Biol Psychiatry. 2020;87(1):82-8.

23. Lloyd K, Cameron E, Williams H, Banister E, Donmall M, Higgins A, et al. Do marketing and alcohol treatment/public health experts think televised alcohol advertisements abide by regulatory guidelines? J Health Psychol. 2020;25(10-11):1657-68.

24. Frączek K, Kowalczyk A, Pekala M, Kasarello K, Sygitowicz G, Sulejczak D, et al. The positive and negative outcome of morphine and disulfiram subacute co-administration in rats in the absence of ethanol challenge. Pharmaceutics. 2020;13(1).

25. Frankowska M, Filip M, Przegalinski E. Effects of GABAB receptor ligands in animal tests of depression and anxiety. Pharmacol Rep. 2007;59(6):645-55.

26. Smaga I, Pomierny B, Krzyzanowska W, Pomierny-Chamiolo L, Miszkiel J, Niedzielska E, et al. N-acetylcysteine possesses antidepressant-like activity through reduction of oxidative stress: behavioral and biochemical analyses in rats. Prog Neuropsychopharmacol Biol Psychiatry. 2012;39(2):280-7.

27. Paxinos $\mathrm{G}$, Watson $\mathrm{C}$. The rat brain in stereotaxic coordinates. 4th ed. Cambridge: MA, Academic Press; 1998.

28. Wydra K, Golembiowska K, Zaniewska M, Kaminska K, Ferraro L, Fuxe K, et al. Accumbal and pallidal dopamine, glutamate and GABA overflow during cocaine self-administration and its extinction in rats. Addict Biol. 2013;18(2):307-24.

29. Koob GF, Le Moal M. Drug addiction, dysregulation of reward, and allostasis. Neuropsychopharmacology. 2001;24(2):97-129.

30. Mierzejewski P, Koros E, Goldberg SR, Kostowski W, Stefanski R. Intravenous self-administration of morphine and cocaine: a comparative study. Pol J Pharmacol. 2003;55(5):713-26.

31. Thompson T, Pickens R. Stimulant self-administration by animals: some comparisons with opiate self-administration. Fed Proc. 1970;29(1):6-12.

32. Liu Z, Zhang JJ, Liu XD, Yu LC. Inhibition of CaMKII activity in the nucleus accumbens shell blocks the reinstatement of morphine-seeking behavior in rats. Neurosci Lett. 2012;518(2):167-71.

33. Mierzejewski P, Stefanski R, Bienkowski P, Kostowski W. History of cocaine self-administration alters morphine reinforcement in the rat. Eur J Pharmacol. 2007;562(1-2):77-81.

34. Vassoler FM, Wright SJ, Byrnes EM. Exposure to opiates in female adolescents alters mu opiate receptor expression and increases the rewarding effects of morphine in future offspring. Neuropharmacology. 2016;103:112-21.

35. Ucha M, Coria SM, Nunez AE, Santos-Toscano R, Roura-Martinez D, Fernandez-Ruiz J, et al. Morphine self-administration alters the expression of translational machinery genes in the amygdala of male Lewis rats. J Psychopharmacol. 2019;33(7):882-93.

36. Zhang H, Jia M, Wang XW, Ye C, Li Y, Wang N, et al. Dentate gyrus mu-opioid receptor-mediated neurogenic processes are associated with alterations in morphine self-administration. Sci Rep. 2019;9(1):1471.

37. Ahmed SH, Koob GF. Transition from moderate to excessive drug intake: change in hedonic set point. Science. 1998;282(5387):298-300.

38. Liu Z, Liu XD, Zhang JJ, Yu LC. Increases in alphaCaMKII phosphorylated on Thr286 in the nucleus accumbens shell but not the core during priming-induced reinstatement of morphine-seeking in rats. Neurosci Lett. 2012;526(1):39-44.

39. Zhang JJ, Kong Q. Locomotor activity: A distinctive index in morphine self-administration in rats. PLoS One. 2017;12(4):e0174272.

40. Maj J, Przegalinski E. Disulfiram and some effects of amphetamine in mice and rats. J Pharm Pharmacol. 1967;19(5):341-2.

41. Maj J, Przegalinski E, Wielosz M. Disulfiram and the drug-induced effects on motility. J Pharm Pharmacol. 1968;20(3):247-8.

42. de Moura FB, Kohut SJ, Bergman J. Limited modulation of the abuse-related behavioral effects of d-methamphetamine by disulfiram. Exp Clin Psychopharmacol. 2018;26(5):497-502.

43. De La Garza R, 2nd, Bubar MJ, Carbone CL, Moeller FG, Newton $\mathrm{TF}$, Anastasio NC, et al. Evaluation of the dopamine beta-hydroxylase (DbetaH) inhibitor nepicastat in participants who meet criteria for cocaine use disorder. Prog Neuropsychopharmacol Biol Psychiatry. 2015;59:40-8.

44. Gaval-Cruz M, Weinshenker D. mechanisms of disulfiraminduced cocaine abstinence: antabuse and cocaine relapse. Mol Interv. 2009;9(4):175-87.

45. Devoto P, Flore G, Saba P, Bini V, Gessa GL. The dopamine beta-hydroxylase inhibitor nepicastat increases dopamine release and potentiates psychostimulant-induced dopamine release in the prefrontal cortex. Addict Biol. 2014;19(4):612-22.

46. Cooper DA, Kimmel HL, Manvich DF, Schmidt KT, Weinshenker D, Howell LL. Effects of pharmacologic dopamine beta-hydroxylase inhibition on cocaine-induced reinstatement and dopamine neurochemistry in squirrel monkeys. J Pharmacol Exp Ther. 2014;350(1):144-52.

47. Anderson SM, Bari AA, Pierce RC. Administration of the D1-like dopamine receptor antagonist $\mathrm{SCH}-23390$ into the medial nucleus accumbens shell attenuates cocaine priming-induced reinstatement of drug-seeking behavior in rats. Psychopharmacology. 2003;168(1-2):132-8.

48. Anderson SM, Schmidt HD, Pierce RC. Administration of the D2 dopamine receptor antagonist sulpiride into the shell, but not the core, of the nucleus accumbens attenuates cocaine priminginduced reinstatement of drug seeking. Neuropsychopharmacology. 2006;31(7):1452-61.

49. Holtzman-Assif O, Laurent V, Westbrook RF. Blockade of dopamine activity in the nucleus accumbens impairs learning extinction of conditioned fear. Learn Mem. 2010;17(2):71-5. 
50. Self DW, Choi KH. Extinction-induced neuroplasticity attenuates stress-induced cocaine seeking: a state-dependent learning hypothesis. Stress. 2004;7(3):145-55.

51. Wise RA, Robble MA. Dopamine and Addiction. Annu Rev Psychol. 2020;71:79-106.

52. Devoto P, Flore G, Saba P, Frau R, Gessa GL. Selective inhibition of dopamine-beta-hydroxylase enhances dopamine release from noradrenergic terminals in the medial prefrontal cortex. Brain Behav. 2015;5(10):e00393.

53. Weinshenker D, Schroeder JP. There and back again: A tale of nor-epinephrine and drug addiction. Neuropsychopharmacology. 2007;32:1433-5.

54. Petrakis IL, Carroll KM, Nich C, Gordon LT, McCance-Katz $\mathrm{EF}$, Frankforter T, et al. Disulfiram treatment for cocaine dependence in methadone-maintained opioid addicts. Addiction. 2000;95(2):219-28.

55. Kosten TR, Wu G, Huang W, Harding MJ, Hamon SC, Lappalainen $\mathrm{J}$, et al. Pharmacogenetic randomized trial for cocaine abuse: disulfiram and dopamine beta-hydroxylase. Biol Psychiatry. 2013;73(3):219-24.

Publisher's Note Springer Nature remains neutral with regard to jurisdictional claims in published maps and institutional affiliations. 